\title{
Briefe von Friedrich von Gentz aus den Jahren $1805-1808$.
}

\author{
$\mathrm{M}$ i t g e th e i l t \\ von
}

Alfred Stern.

Die nachfolgenden Briefe Friedrichs von Gentz entstammen dem Public Record Olfice in London. Dank der Liberalität des Foreign Office ward es mir erlaubt, auch dort Materialien für meine „Geschıchte Europas“ zu sammeln. Bei dieser Gelegenheit wurde meine Aufmerksamkeit auf mehrere Aktenbände mit der Bezeichnung Austria gelenkt, die aus dem Zeitalter Napoleons herrühren. In zweien derselben (Nr. 76 und 87) trat mir die Handschrift Friedrichs von Gentz entgegen. Den eigenhändigen Briefen des grossen Publicisten relht sich ein von ihm verfasster Brief (Nr. XI) von der Hand eines Schreibers an. Auch eine grosse Denkschrift, die in Band 76 den Briefen vorausgeht, weist die Hand eines Kopisten auf. Nur die Schluss-Notiz: „Présenté le 6. Sept. 1804" stammt von Gentz' eigener Hand. Diese Denkschrift ist nichts anderes als das beredte Memoire, welches Gentz am 6. September 1804 dem Erzherzog Johann überreicht hatte. Wie man weiss, wurde es im Vertranen durch einen eigenen Boten dem Grafen Starhemberg, dem österreichischen Gesandten in Lnnilon, zugesandt, mit welchem Gentz seit seinem Londoner Aufenthalt in Jahre 1802 freundschaftlich korrespondirte ${ }^{1}$ ). Vermutlich gelangte es durch

1) Fournier: Gentz und Cobenzl Wien 1880. S. 137, daselbst S. 242-292 der wörtliche Abdruck der Denkschrift. - A. Graf Thür heim: Ludwig Furst Starhemberg. Graz 1889 S. 152, daselbst S. 321-359 der Abdruck der von Gentz an Starbemberg 1805 und 1806 gerichteten Briefe, die zuerst in des Mittheilungen de.s lnst. f. osterr. G. 1886. VII 119-155 erschienen. 
ihn in Besitz des Foreign Office. Auch dass Gentz seit jener Reise, die ihn den bedeutendsten englischen Staatsmännern nahe gebracht, mit vielen von ihnen in regem Briefwechsel stand, ist bekannt genug. Eine lange Liste seiner vornehmen euglischen Korrespondenten aus dem Zeitraum von 1803 bis zum Ende des Jahres 1807 findet sich nach seinem ersten "Portefeuille" bei Schlesier (Schriften von Friedrich ron Gentz V. 29). Allein auf Vansittart, als Adressaten, kommen hier 31 Briefe. Nach demselben Gewährsmann (V. 30) finden sich vom Jahre 1808 an $u$. a. , viele Briefe ${ }^{k}$ an Canning im ,zweiten Portefeuille" aufgezeichnet.

Von diesem ganzen Reichtum scheinen sich nur wenige Trümmer in das Londoner Record Office gerettet zu haben. Diese aber, soweit sie zu meiner Kenntnis gekommen sind, bieten ein sebr huhes Interesse dar. Wie man ohne weiteres vermuten wird, spielen die Geldangelegenheiten Friedrichs von Gentz in ihnen eine Rolle. Indessen treten sie hinter den grossen Gegenständen der Politik durchaus zurïck. Es kann dem Herausgeber nicht obliegen, im einzelnen nachzuweisen, inwieweit bei ihrer Behandlung Gentz sich als kundig und scharfblickend erweist, und wo er, mangelhaft unterrichtet oder voreingenommen, irrt. Auch wäre ein ausführlicher Kommentar, wenigstens, wo von allbekannten Ereignissen oder Persönlichkeiten die Rede ist, nicht am Platz. Zudem berühren sich einige der Briefe mit schon gedruckten, wie den an J. von Müller und Starhemberg gerichteten. Von den Adressaten ist Canning, seit 1807 Staatssekretär für das Auswärtige im Ministerium Portlund, weitaus die bedeutendste Persönlichkeit. Sein Name bedarf keiner Erläuterung. Vor ihm erscheint auf deu folgenden Blättern als einer der englischen Staatsmänner, mit denen Gentz in brieflichem Verkehr stand, George Hammond. Dieser Mann (1763-1853) war, nachdem er als Diplonat in Paris, Wien, Kopenhagen, Madrid, Philadelphia sich seine Sporen verdient hatte, 1795 Uuterstaatssekretär im auswärtigen Amt geworden und blieb in dieser Stellung bis zur Bildung des Ministeriums Grenville-Fox im Jahre 1806. In jene Zeit fielen wieder diplomatische Missionen, die ihn nach Berlin, Wien und nochnals 1805 nach Berlin führten. Als sein Freund Canning 1807 das Auswärtige übernahm, trat Hammond wieder als Unterst: atssekretär ein und biieb in dieser Stellung bis zur Anflösung des Ministeriums Portland zu Ende des Jahres 1809 ${ }^{1}$ ). Dass Gentz ihn schon von seinem Loudoner Aufenthalt her persönlich kannte, ist wahrscheinlich. Sicher bezeugt ist es von eivem anderen

1) S. Dictionary of National Biography XXIV. 241 rgl. Bailleu: Publikationen aus den k. Preuss. Staatsarchiven VIll. 458, 532. 
der im Folgenden vorkommenden Adressaten: Nicholas Vansittart (1766-1851), im Ministerium Addiugton 1801-1804 Sekretär des Schatzamtes, im Januar 1805 zum Secretär für Irland ernannt, unter Grenville wieder Sekretär des Schatzamtes, vom März 1807 an mehrere Jahre ausser Amt, bis er 1812 Schatzkanzler wurde 1). Die Adressaten der Briefe IV. IX. $\mathbf{X}$ lassen sich nur vermuthen. Derjenige des Briefes $\mathbf{X}$ könnte am ehesten G. Hammond sein, derjenige des Briefes IV Lord Hawkesbury, der unter dem Namen Lord Liverpool (1770-1828) in der allgemeınen Geschir hte bekannt ist, in Ministerium Addington Sekretär des Auswärtigen, beim Wiedereintritt Pitts 1804 Sekretär des Innern 2). Für den Brief IX bietet sich am ungezwungensten als Adressat Juord Harrowby $\left.{ }^{3}\right)(17(j 2-1 \times 47)$, als Pitt 1804 wieder eintrat für kurze Zeit Sekretür des Auswärtigen, Ende 1805 mit G. Hammoud auf einer diplomatischen Mission nach Berlin gesandt (s. u.). - Die Schreibung ist, wo Gentz' Original vorlag, nicht verändert worden.

I.

Gentz an Hammond.

\section{Monsieur!}

Vienne le 7 Mai 1805.

Je m'adresse à Vous avec la même confiance, avec laquelle je parlerois à un ancien ami. Je sais depuis long-tems que vous partagez la bienveillunce dunt tant de personnes intéressantes m'bonorent dans votre patrie, et l'objet même que je dois traiter ici, quoique momentunément pénible. est un de ceux qui m'ont prouvé, que je ne me trompois pas on comp'ant sur Vos bontés.

Il vous est connu que j'avois envoyé un homme en Angleterre, et que je l'avois pisticulièrement recommandé à $\mathbf{M}^{\mathrm{r}}$. V. ${ }^{4}$ ) en le priant instamment de faire remettre à cet homme une partie du moins des fon'ls ıui m'étuient de.itinés. Par une lettre que je reçois bier de lui, j'apprends qu'on en a autrement disposé. Cette circon -tance me met dans le plus cruel embarrus: 1. puisque l' homme en que.tion étoit chargé de ma part de faire plusieurs payemens urgens, et que l'impossibilité de les faire nonseulement l'empêche de partir de Londres - chose plus importante pour moi que je ne saurois vous détailler dans cette lettre, qui va en granle partie par la poste ordinaire - mais encore porte un coup funeste à mun crédit. 2. puisque, li maison de Coutts ${ }^{5}$ ) ne m'ayant

J) S. Dictionary of National Biography LVIIL, 140.

2) S. Di.tionary of National Biography XXIX. 311.

3) S Dictionary of National Biography L. 4\%.

9) Ohıe Zweitel Vansittart.

6) 'Ihomas Cintts (1745 18:2) mit seinem Bruder James Gründer des Bankhiuses Contts \& Co. in London s. Dictionary of National Biograp'hy XII. ¿.5t. 
pas même donné le moindre avis des payemens à eux faits, je me trouve dans une espèce de cahos [sic] et de labirinte, où je ne vois ni entends rien. Je viens donc d'adresser une lettre à $\mathrm{Mr}$. V. pour réclamer encore une fois ses bontés; mais ne sachant pas, si cette lettre le trouvera encore à Londres, et supposant avec raison, que Votre influence dans toute cette affaire est assez directe et assez puissante pour tout décider sur-lechamp, c'est a Vous principalement que je m'en remets pour le succès de ma demande. - Il s'agit de me faire obtenir encore 500 L. St. et de les faire payer entre les mains de l'homme qui présentera cette lettre, et qui est tellement muni de mes pleins-pouvoirs que ce sera absolument comme si cet argent m'avoit été remis à moi-même. $\mathrm{Si}$ vous faites réussir cette dernière demande, le tort que m'a fait, et les embarras que me crée la circonstance de tous les payemens fuits à Coutts, seront réparés; mon commissionnuire pourra partir, mon crédit sera soutenu, et je vous en aurai une reconnoissance, qui ne finira qu'avec ma vie.

J'ajouterois très volontiers quelques observations sur un antre objet, qui, quoique ne m'étant pas personnel, m'intéresse plus que tout ce qui m'est personnel, si, comme je l'ai déja dit cette lettre partoit par une voie plus sure. Mais, je vous demande en grace un mot de votre part, pour savoir si je puis vous adresser en toute liberté une autre lettre qui sera consacrée à cet objet.

Pour aujourd'hui je vous recommande avec les plus vives instances l'objet et l'auteur de celle-ci, en vous priant d'agréer les hommages de la trèsrespectueuse considération et du dévouement bien profond avec lequel je suis

\section{Monsieur \\ votre très-obéissant serviteur \\ Gentz.}

P. S. Si par quelque changement imprévu mon homme avoit trouvé le mojen de partir sans avoir reçu quelque chose de votre part, ce seroit encore un soulagement extrême, si vous pouviez faire pilyer, ou du moins prcmettre de payer à Mrs. Coutts cette somme additionelle de 500 L. St.; pour que je conserve la liberté de m'adresser à eux; car je crains, que mojennant l'arrangement qui paroit avoir été fait, je ne me tirerai pas d'affaire sans cela.

II.

\section{Gentz an Vansittart.}

Vienne le 13 Mai 1805.

Je suis désolé, Monsieur, qu'après toutes les peines, que je Vous ai données, et après toutes les bontés que Vous avez eues pour moi, je me trouve encore dans le cas de Vous importuner par des affaires particulières.

Je viens de recevoir dans ce moment même une lettre du 12 Avril, écrite par l' homme qui $m$ 'a servi jusqu' ici d'intermédiaire pour ma correspondance, et qui me mande que malgré une promesse gracieuse qui lui avoit été faite de votre part, tous les fonds a moi destinés, avoient été payés entre les mains de Mrs. Coutts; que rien ne lui en étoit parvenu; 
et que n' étant mani de rien pour Mrs. Coutts, et ne pouvant pas prévoir cet incident, il est dans le plus cruel embarras par rapport aux commissions que je lui avois données. Vous imaginez bien que cet embarras retombe sur moi dans toute son étendue, et cela d'autant plus que je n'ai pas neème de la part de Mrs. Coutts un mot d'avis sur aucun payement fait it leur maison.

Il m' est impossible de deviner ce qui a pu amener cet arrangement, malgré les instances pressantes et réitérées que je Vous avois arlressées à ce sujet, et malgré la confiance absolue que Vous auriez pu accorder à un homme que je Vous avois désigné comme aveuglement attaché à mes intérêts. Comme je n' ai reęu aucune explication quelconque, qui puisse me guider dans cette affaire je dois me contenter de la persuasion, que ce qui s' est passé, doit avoir été nécessaire, puisque $\nabla$ ous l'avez approuvé. Mais ma position n' en devient pas meilleure.

J'avois avec la maison de Coutts des engagemens de différentes espèces, dont quelques-uns m'étoient rien moins que pressans. Maintenant il est clair, qu' ils se rembourseront sur-le-champ de tout ce qui leur revient, et que des arrangemens qui me touchoient de plus près, seront devenus impossibles. Ce coup li est vraiment funeste pour moi. Mais peut-etre qu'il y a encore moyen de le réparer en partie: Comme Vous avez tant fait pour moi, Vous et Vos amis, ajoutez encore un bienfiit peu considérable à tous ceus que je Vous dois. Mettez cet homme, que j'avois envoyé à Londres, et dont $j$ 'attends le retour avec tant d'impatience, en état de partir, après avoir réglé mes affuires. Avec une somme additionnelle de 500 L. St. il pourra s' arranger pour cet effet. Faites-moi la seule et dernière grace de lui faire remettre (mais à $l u i$, et directement à lui) cette somme, comparativement à tout ce que Vous avez accordé dans cette occasion inconsidérable, et surtout veuillez bien, je Vous en conjure, la lui faire remettre sans beaucoup de délai. Si toutefois il étoit parti de Londres, comme il n'aura pu le faire que par quelque arrangement embarassant ou funeste pour mon crédit, veuillez la faire remettre encore, ou du moins promettre à la maison Coutts, pour que je conserve la liberté de tirer sur eux pour cet objet; car je crains que par les payemens antérieurs je n' aurai pas beaucoup rétabli mes affuires, à-moins que Mrs. Coutts n' en usent avec moi d' une délicatesse tout-à-fait particulière.

Je suis incapable de traiter d' autres objets dans cette lettre, [qui] quoique transportée par une occasion particulière jusqa'à Prague, n' en a pas moins beaucoup de chemin a faire par la poste. Le silence que tout-le-monde garde avec moi, est bien fait pour me désorienter et même pour me décourager; mais il ne produira ni l' un, ni l' autre de ces effets. Je m'en tiens à un sentiment ineffuçable, qui me dit, que, malgré ce terrible silence, je vis dans Votre souvenir, et dans celui de Vos amis; cette conviction ne me quittera pas de si-tôt; et si même elle me quittoit à-la-fin (ce qui à Dieu ne pluise!) il me resteroit encore des motifs bien sacrés, pour continuer sans interruption la carrière que je me suis tracée, et que je suivrai avec une ardeur toujours égalè jusqu' à ma dernière heure, ou jasqu'à celle de tout ce qui mérite les voeux, le dérouement, et les sacrifices les plus décisifs de la part de l' brmme-de-bien, qui doit se refuser à-jamais de désespérer de la chose publique. 
Cependant quelques lignes de Votre main me donneront un renfort de courage dont j' ai grandement besoin. Je Vous les lemande avec le mơne empressement, mais aussi avec la même confiance illimitée, avec lsquelle je Vous recommande l' objet et l'auteur de cette lettre.

Votre très fidele serviteur

G.

P. S. Ne pouvant pas juger de Vos projets personnels, dans l' ignorance absolue où je me trouve sur ce qui Vous concerne, au-moins ne partez pas de Londres je vous en conjure, sans avoir fait ce que je Vous ai demandé avec tant $d$ 'instance sur les moyens de maintenir ma correspondance pour l'avenir.

\section{III. \\ Gentz an Hammond 1). \\ Vieune le 19 Juin 1805.}

Monsieur!

Je viens de recevoir une lettre de $\mathrm{M}^{\mathrm{r}}$. Vansittart, qui me dit, que ví son départ prochain pour l'Irlande, je duis desormais adresser à Vous en toute confiance les avis, réflexions, ou demandes, que $j$ ' avois fait parrenir jusqu'ici par son intervention aux Ministres de Sa Ilajesté Brittannique.

Cette direction, je Vous l'avoue, Monsieur, m'a fait le plaisir le plus sensible; elle est conforme à la confiance que j'ai toujours eu en Vous, sans me trouver plus particulièrement honoré $d$ 'une liaison directe; elle est conforme à la haute idée que j' ai de Vos lumières, de Votre caractère, et de . Votre zèle pour les intérêts de Votre noble patrie; et, espérant que vous voudrez confirmer directement la permission que Mr. Vansittart vient de me donner, je l'ai anticipée, sans crainte de Vous déplaire, en réclamant déjà vos bontés pour une affaire privée, sur laquelle j'ai pris la liberté de Vous écrire le 8 de $\mathrm{Mai}^{2}$ ).

Aujourd' hui il s'agit d'une chose, dont j'ai instruit Mr. Vansittart, il y a quelque tems, mais qui doit se réaliser bientôt, si Vous la jugez digne de Votre protection. Je viens de composer un ouvrage „sur l' origine et les causes de la guerre présente entre l' Espagne et l'Angleterre ${ }^{3}$ ) * ouvrage, dans lequel j'ai dévelıppé et traité à-fond un ob;et, qui est extrémement intéressant sous le rapport de l'opinion publique. Aucun événement récent $n$ 'a été si indignement défiguré, déchiré, et perverti; aucun n'a excité contre Vous des clameurs plus générales, et plus inturissables; et quoique depuis long-tems les plus infames calomnies soient constamnent à $l^{\prime}$ orire du jour contre Vous, et que le public de tous les pays les acceuille et les gobe avec une crédulité vraiment bonteuse, j'o:e cepentant dire que celles qu' on a répandues, et qu' on ne cesse de répandre par rapport à cette guerre d'Espagne surpassent en malignité et en im-

1) Die Adresse fehlt, aber der Inhalt des Briefes ergiebt, dass Hammond der Adressit war.

2) Vielmebr 7. Mai s. o. S. 109.

8), Anthentische Darstellung des Verbältnisses zwischen England und Spanien vor und bei dem Ausbruch des Krieges zwischen beiden Mächten . Petersburg (Leipzig) $180 t$. 
pudence tout ce qu' on a jamais inventé de pareil. Je crois done avoir ne pas démenti de l'Angleterre en choisissant ce sujet-là pour l' examiner avec la dernière rigueur, et pour prouver. toujours pièces-en-main, que tout, ahsolument tout a été fuux duns ces accusations du commencement jusqu'à la fin, et que la conduite des deux Ministères qui se sont succédés, a été invariablement juste, pure, modérée. magnımine et irréprochable à tout égard. J'ai saisi en même tems l'occasion pour parler en général de l'atrocité de ces diatribes continuelles que le Moniteur vomit contre Vous sans relâche et qui font depuis quelyue tems son pain quotidien. J'ai expliqué dins une préface composée ad hoc, quelle est proprement le caractère et le but de ces diatribes; et j'ai bien fait sentir, que $j$ ' uvois chuisi exprès un exemple fameux (tel que la guerre d'Espragne) pour prouver que même dans un cas où l'opinion de tous les pays paroissoit seconder (par ignorance et précipitation) les calomnies des Françoì, où elles ont prodıit leur effet complet - que même dans ce cas-là elles étoient dénuées de toute ombre de fundement. „Crimine ab uno di ice omnes!*

Cet ouvrage entièrement achevé $s$ 'mprime dans ce moment à Berlin; et je le ferai répandre autant que possible en Allemagne: c'e-t dans cette vue que je l'ai composé aussi en Allemand. la France étant si hermétiłuement fermée que rien ne peut passer ses frontières. Nais mon amlition s'étend plus luijn encore. Je suis persualé que cet ouvrage produiroit de l'effet en Angleterre, où on a reçu quelques autres de ma plume avec tant d'indulgunce et de faveur. Je m'en flatte d'autant plus, que, les membres le l'opposition ayant malheureusement adopté la plus grande partie des fatusses idées qu' on avoit établies en Europe sur l'origine de cette guerre, l'opinion publique de l'Angleterre elle-même a été considérablement entrainée, et mérite certainement 'l'être écluirée, et même un peu ramenée sur cet objet. Si trut ne me trompe, cet ouvrage y réussira sous ce point-de-vue. Je ne le dis pas par une vanité puérile; mais après avoir profunilément étu lié la question, j' ii trouvé la cause de l'Angleterre tellement bonne, tellement forte (au delà même de ce que je l'avois cru moi-même) que cette conviction, je dirois presque cette décu uverte $m$ ' a fait travailier avec un zèle sans hornes, et $m$ 'a présagé et presque garanti le succè;. Je sais bien, que je ne puis pas Vous prouver d'avance, ce que je soutiens ici; mais je me flatte que Vous m'en civirez.

Il s'agit done de trouver en Angleterre un tralucteur hulile. Il en existe un, que je crois le premier de tuas; celui qui a bien voulu traduire mon ouvrage sur l'état de l' Eurupe. C'e et Mr. Herries ${ }^{1}$ ), attaché

1) John Charles Herries (1778-1855) Staatsmann s. Dictionary of $\mathrm{Na}$ tional kiography XXVI. 255, sent 1801 l'rivatsekretär Vansitturts. Er hatte 180.2 Gent\%' Schrift, Von dem potitiselien Lustand von Europa" u s. w. ins Englische übervetzt. Nach einem bei den Lonıloıer Akten luefin lichen Briefe Vansitarts an Hammond vom 13. Juli 1811 war jener bereit, Gentz' Wuns h

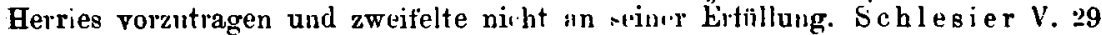
gielst an. Herries babe, $\mathrm{mehrere}$ Schrifien" von (ientz ïbersetat und Haym (Artikel Gentz in Fisch and Grobers Encyklopädie S. 3H) rrhresut

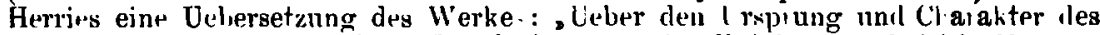
Kripges gigen die französische Revolution " zul. Im Katalog ie's British Museum ist keine englische Uebersetzung vou Gentz' Schmft , Authentische Darstellunge 
alors à la trésorerie, dont je ne connois pas dans ce moment la situation et les fonctions, mais dont la bonne volonté ne $m$ 'est pas douteuse, et qui m'a même assuré il y a quel pue tems, qu' il se prêteroit avec plaisir à un travail de cette espèce. Si Vous pouvez engager celui-ci, mon affaire est faite. Si d'autres occupations l'en empêchent, il ne se refusera pas du moins à indiquer quelqu' un qui pourroit s'en charger à sa place, et à diriger l'exécution. Si $\mathbf{M}^{\mathbf{r}}$. Herries n'étoit plus à Lonilres, ou si quelque dérangement avoit eu lieu dans sa situation, enfin s'il est impossible de l' intéres ier à cette entreprise, je Vous proposerois très-humblement d'en faire parler à Mr. Herbert Marsh ${ }^{1}$ ), que Vous connoissez probablement vous-même, ou dont Vous pourriez aisément apprendre l'adresse par $\mathbf{M}^{\mathbf{r}}$. Yorke ancien Ministre de la guerre ${ }^{2}$ ), avec lequel il étoit lié de mon tems. Enfin, Monsieur, persuadé que je suis, que Vous ne Vous répentirez jamais de la protection que Vous aurez accordée à cette affaire, je Vous la recommande de la manière la plus pressante, et je vous prie sur-tout de la mettre en-train aussitôt que possible, pour que celui qui voudra se charger de la traduction, ait le tems de s'y préparer. Les feuilles de l' ouvrage Allemand Vious seront adressées à-mesure qu' elles sortiront de la presse par $\mathrm{Mr}^{\mathbf{r}}$. Jackson, qui les recevra des mains du libraire ${ }^{3}$ ).

Je n'ai aucun doute sur le succès de l'autre affaire que j'ai eu l'honneur de Vous présenter dans ma lettre du 8 Mai 4). J'ai reçu tant de preuves de bienveillance de la part de Votre gouvernement, que je n' ai pas eu le tems d'apprendre ce que c'est que la crainte d' un refus.

$\mathrm{Si} \mathrm{Mr}^{\mathrm{r}}$. Vansittart est encore en Angleterre lorsque cette lettre Vous parviendra, je Vous prie de vouloir bien lui en communiquer le contenu, et de me recommander à ses bonnes graces. Dans quelques jours d'ici je profiterai du départ de $M$. le Général Ramsay ${ }^{5}$ ) pour vous prier de présenter à $\mathbf{M}^{r}$. Pitt une lettre que j'aurai l' honneur de Vous adresser sur un ohjet tout particulier. En attendant je Vous présente, Monsieur, l' hommage de tous les sentimens distingués, de la haute considération, et du dévouement parfait, avec lequel je suis

\section{Monsieur !}

Votre très-humble et très-obéissant serviteur

Gentz.

u. s. w. vorhanden. Auch Watts: Bibliotheca Britannica 1824. I. giebt nur den englischen Titel des deutschen Originales an, ohne einer Uebersetzung zu gedenken.

1) Herbert Marsh (1757-1839) Verfasser des Werkes: „History of the Politics of Great Britain and France from the time of the conference of Pilnitz to the declaration of war against, Great Britain 1799 , das zuerst in deutacher Sprache ge-chrieben war (auszugsweise von Gentz in seinem, historischen Journal veröffentlicht), narbmals Bischof von Peterborough s. Dictionary of $\mathrm{Na}$ tional Biography XXXVI. 211.

2) Charles Yorke, Graf Hardwicke. Vgl. Stanhope: Life of Pitt.

s) Sir George Jackson (178a-1 -61) damals Geschäftsträger in Berlin. Briefe von Gentz an ihn sind enthalten in seiuen, Diaries and Letters", The Bath.Archives\& 1873.

4) S. S. 112 Anm. 2.

5) Vielleicht George Ramsay (1770-1838). Kommandant der siebenten Division der britischen Armee in Epanien und Frankreich 1812-1814 s. Dict. of National Biography XLVII. 247. 
IV.

Gentz an Hawkesbury ${ }^{1}$ ) [?].

Vienne le 17 Aout. 1805 .

Monsieur!

Quoique je n' aie pas l'honneur de Vous être personnellement connu, je suppose cependant que mon nom ne vous est pas tout-à-fait étranger; el ce qui m' engage à Vous écrire est d'ailleurs de nature à m'assurer dans tous les cas une réception bienveillante.

J' ai reçu depuis quelque tems plusieurs lettres de la part d' un homme, dont j' ignorois jusques l' existence, mais qui s' est imaginé que moyennant quelques liaisons dans lesquelles je me trouve avec des personnes distinguées de l'Angleterre je pourrois contribuer quelque chose à son soulagement. J'ai voulu d'abord me soustraire à ses importunités; mais il en a tant fait, qu' à la fin j'ai dû me rendre. Je lui ai donc promis, de Vous faire parvenir la lettre ci-jointe; c' est à Vous à juger, si cet homme mérite votre secours et si vous pouvez faire quelque chose pour le tirer de la triste position, dans laquelle il paroit se trouver.

Mais je dois bien autrement compter sur votre indulgence, lorsque je saisis cette occasion, pour Vous parler d' un oljet, qui vous regarde plus particulièrement. Pour peu que Vous connoissiez mes relations et le but de tout mon existence, Vous saurez que je me suis voué depuis quinze ans ì une guerre-à-mort contre les pris.cipes - et (depuis qu' il n' est plus question de principes) contre les résultats de la plus exécrable révolution que jamais le monde ait vu naitre. En recueillant tous les matériaux, pour former un jour le grand acte d'accusation contre l' atroce tyran qui gouverne la France à-présent, je me suis souvent occupé, comme Vous imaginez bien, de la fameuse affaire dans laquelle on Vous a fait jouer un rôle. Cette affaire est sous tous les rapports une des plus mémorables de notre tems, puisque c'est elle qui a donné immédiatement le prétexte, sous lequel cet audacieux usurpateur s' est emparé du titre d'Empereur; et il faut absolument que tôt ou tard elle soit développée dans tous ses détails. Pour ceux, qui veulent trouver la vérité, l'ouvrage de cet archi-scélérat Méhée étoit déjà la justification la plus complète qu' on ait pu publier de votre conduite ${ }^{2}$ ). Mais je Vous avoue, que je me croirois singulièrement heureux, si je pouvois obtenir de Vous-même quelques éclair-

1) Die Adresse fehlt. Ich vermute, dass Lord Hawkesbury, damals Staatssekretär des Inneren, der Anressat ist, da er durch die Schrift von Méhée de la Touche (s. u. Anm. 2) mitbetroffen war. Auch wird er in dem Briefverzeichnis bei Schlesier V. 29 als einer der Empfänger Gentz'scher Briete in dieser Zeit genannt.

2) Es handelt sich um die Schrift des berüchtigten Mébée de la Touche (1760-1828): Alliance des Jacobins de France avec le ministère anglais; les premiers représentés par le citoyen Méhée, et le ministère anglais par $\mathbf{M}$. $\mathbf{M}$. Hammond, Yorke, les lords Pelham et. Hawkesbury etc. Paris Germinal an XII. Die , affiaire auf die Gentz anspielt, ist die der Verschwörung Cadoudals, der Processe Pichegrus und Moreans, der Érschiessung des Herzogs ron Enghien etc. S über Méhée de la Touche, der sich gleichzeitig als Agent der Royalisten und als Spion der französischen Regierung hatte bezahlen lassen, Lanfrey : Histoire de Napoléon I. Vol III. $89 \mathrm{ff}$. L. Lala nne: Les derniers jours du Consulat. Manuscrit inédit de Fauriel $1886 \mathrm{~S} .124 \mathrm{ff}$. 
cissemens authentiques sur toute la marche de cette affuire. En Vous les demandant, Monsieur, Vous sentez bien que rien ne peut être plus éloigné de moi que l'idée de Vous compromettre. Habitué depuis longtems à connoitre et à garder des secrets politiques de la plus haute importance, et intimement lié avec des hommes d'état de plusieurs pays, et nommément vos compatriotes, je regarderois ce que Vous me confierez comme un dépôt sacré dont je ne ferois usuge que sous les restrictions que Vous y ajouteriez Vous-même, et dans l'époque, où cela peut porter coup. Dans tous les cas, Vous sentez bien, que rien au-monde ne m' engageroit à publier une seule circonstance qui peut Vous être défavoruble; je suis convaincu d'avance qu' il n' en existe pas, et que Vous ne pouvez que gagner à un récit fidèle. Mais je ne me presserai point de le donner au public; c' est pour le moment, où nous pourrons respirer, où l'espoir de nous venge $r$ enfin sera à la-veille de se réaliser, c' est alors seulement que je ferai usage de vos renseignemens.

Je Vous demande pardon de l'assurance et de la bardiesse avec laquelle je Vous adresse cette prière. Mais je connois depuis si longtems Votre zèle pour le bien, Votre activité écluirée, Vos talens distingués et Votre dévonement à la cause des principes et de l' honneur, j'ai si souvent entendu parler de Vous, et j'ai si souvent lu de Vos lettres que c'est absolument comme si je me trouvois avec Vous dans une liaison très-ancienne. Je vous prie de remettre la réponse, dont Vous m' honorerez a $\mathrm{Mr}$. Hummond, ou bien de l'adresser directement à Sir Arthur Paget, par lequel je la recevraj sans délai ${ }^{1}$ ). Au-reste que Vous jugiez convenable de faire ce que je demande, ou que Vous ayiez des olijections que je respecte d'avance par cela seul qu' elles Vous arrêteroieut, permettez moi de croire que Vous interprèterez en bien la démarche que je virns de faire, et agréez l'hommage de la baute considération et du très-parfuit dévouement avec lequel j' ai l'honneur d'être,

\section{Monsieur!}

Votre très-humble et très-obéissant serviteur Io Chevalier Gentz.

V.

Gentz an Hammond ${ }^{2}$ ).

Vienne le 29 Aout 1805.

\section{Monsieur!}

Le Courier qui Vous a apporté ma dernière lettre étoit dejjà parti, lorsque l'idée m'est venue, qu' un des moyens pour accélérer l' affuire que j'avois pris la liberté de Vous recomman:ler plusieurs tois, seroit peut-être de m'alresier directement à Lord Mulgrave ${ }^{3}$ ). Si, en recevant la présente,

1) Arthur Paget (1771 - 1840) Diplomat, von 1801-1806 englischer Gesandter in Wien. s. Dict. of $\mathrm{Nat}$. Biography XLIII. 45.

2) Die Adresse tehlt, aber die Hinweisungen auf frühere $B$ iefe machen es anzweifelhat, dass Hammond der Adressat was.

3) Henry Pbipps erster Graf von Mulgrave (1755-1831), seit Januar 1805 Sekretär des Foreign Office s. Dict. of National Biography XLV. 233 . 
Vous avez déjà eu la bonté d'arranger cette affaire, et de mettre mon commissionnaire en état de partir, cette démarche à la vérité sera superflue; ma lettre cependant est écrite de manière que même dans ce cus-là elle pourroit toujours être remise, si Vous le jugiez convenable. Si la chose n' est pas encore arrungée je Vous réitère mes instances pour que Vous veuilliez bien l' appuyer autant que possible et mettre fin à un embarras, qui deviendroit infiniment pénible, si mon homme ne pouvoit pas partir à présent.

Après cela je prends la liberté de réclamer vos bontés par rapport aux différentes lettres que je Vous ai adressées, Vous priant instamment de $m$ ' honorer d' un mot de réponse, afin que je puisse continuer en sûreté et bonne conscience à Vous adresser de tems-en-tems ce que je cruirai particulièrement intéressant pour votre gouvernement.

En me référant à tout ce que j'ai $\cdot$ dit à cet égard dans mes lettres précédentes, j'ai l' honneur d'être avec la plus respectueuse considération et le dévouement le plus invariable

Monsieur!

Votre très-humble et très-obéissant serviteur

Gentz.

VI.

Gentz an Hammond ${ }^{1}$ ).

Vienne le 23 Octobre 1805.

Monsieur!

La lettre que Vous avez bien voulu m'écrire le 13 de septembre m'a fait sous plus d'un rapport le plus sensible plaisir. Les encouragemens qu' elle me fournit ne seront pas, je vous le promets bien, perdus pour la cause que nous avons à délendre maintenant, et je me ferai un devoir de Vous communiquer le plus souvent possible mes idées sur ce qui se passe autour de moi.

Je suis bien affligé de ce que les premières réflexions que j'ai à Vous présenter depuis l'ouverture de la guerre continentale, doivent se porter sur des objets de regret, et de désolation. Nous avons essuyé de grands malheurs, d'autres nous attendent peut-être; mais le plus grand de tous seroit de s'écarter un seul moment du calme qui est indispensable pour en approfondir les causes, et de la fermeté qui peut seule en arrêter ou diminner les efiets. Nos revers ne nous sont encore que très-imparfaitement connus; des rapports vagues, ténébreux, mystérieux, dans lesquels on ignore ou on cache la moitié de la vérité sont les seuls qui soient parvenus au gouvernement. Cependant les faits principaux sont constatés, et comme ils sont tellement inattendus, que ceux qui ont connu et partagé nos espérances auront de la peine à les concevoir et à les expliquer, je crois faire une chose utile en Vous fournissant dès-à-présent quelques

1) Die Adresse fehlt. Dass George Hammond der Adressat war, ergiebt sich aus dem Hinweis auf die Namensverwechselung im Postscriptum. Zur Vergleichung des Inhaltes dieses Briefes sehe man (ieutz' Schreiben an Starhemberg vom 24. Okt. 1805 (Mittbeilungen des Instituts a. a. O. S. 123) und an J. von Müller vom 23. Okt. 1805 (Schlesier IV. 121). 
données qui serviront à les éclaircir. Ce que j'aurai l'honneur de Vous dire ici n'est pas simplement le résultat de mes conjectures, ou de mes combinaisons, comme je ne suis pas militaire, ce seroit une grande témérité que de vouloir m'en fier à mon jugement dans des affaires pareilles; c'est la substance de ce que j'ai pnisé dans les conversations de quelques personnes particulièrement instruites de tout ce qui se passe aux armées et dans les conseils de guerre, et particulièrement capables de juger les opérations militaires. Absorbé depuis quinze jours par des objets d'une aussi haute importance et n'ayant fait antre chose que de conférer avec ces personnes, je me suis formé, en rapprochant et combinant leurs opinions et leurs renseignemens, une idée que je crois bien correcte de l'état actuel de nos affaires. J'avois communiqué à $\mathbf{M}^{\mathbf{r}}$. Paget une grande partie de ce que j'aurai l'honneur de Vous présenter; mais comme il ne fait que sortir d'une grande maladie, je ne sais s'il aura eu le tems et le courage de s'en servir. Dans tous les cas, j'ajme mieux me répéter que m'exposer à Vous priver de ce qui dans les circonstances actuelles ne sauroit être trop connu, trop examiné, et trop médité par les personnes entre les mains desquelles la providence a mis les destinées des empires.

Ce que nous savons avec certitude sur les événemens, qui ont eu lieu entre le 7 et le 15 Octobre, est renfermé dans les articles suivans:

1. Que la position, que le Général Mack avoit prise le long de l'Iller de $M$ emmingen jusqu'à Ulm a été complètement tournée par l'armée Françoise, dont une partie considérable, composée des corps de Bernadotte, de Marmont, et de D'Avoust, et renforcée par l'armée Bavaroise, (le tout montant pour le moins i 70,000 hommes) s'est portée de Wurtzbourg sur le Murggraviat d'Anspach, et violant le territoire Prussien a gagné par la principauté d' Eichstaedt le Danube qu'ils ont passé le 7 et 8 entre Ingolstadt et Neubourg; pendant que l'autre partie, commandée par Bonaparte lui-même composée des colonnes de Lannes, de Ney, de Soult etc et forte aussi de $\mathbf{7 0 , 0 0 0}$ hommes a défilé par le pays de Wurtemberg, et a passé le Danube dans les environs de Donauwörth, de sorte que dès le $8 \mathrm{du}$ mois toute l'armée s'est trouvée réunie sur une grande ligne entre Je Danube et Augsbourg, attaquant par derrière, et enveloppant pour ainsi dire l'armée Autrichienne, forte tout-au-plus de 80,000 homines.

2. Qu'après des combats sanglans qui ont continué sans cesse dans les journées du $8,9,11,12,13$ et 14, la position de notre armée a été forçée et rompue, et que le soir du 14 (autant que nous pouvons le démêler) le Général $\mathrm{Mack}$ a quitté Ulm, et s'est retiré sur la rive ga u che du Danube.

3. Que dans cette même malheureuse journée il a détaché (de gré, ou par force, on ne le sait pas) le Général Jellachich avec 10 ou 12 mille hommes, pour gagner la frontière du Tyrol, lui ordonnant de prendre avec lui un corps de 11 Bataillons qu'il trouveroit à Memmingen; que l'ordre à ce corps de se réunir au Général Jellachich est arrivé trop lard, ou a été mal-rendu, enfin que tous ces 11 Bataillons sont tombés entre les mains de l'ennemi.

4. Qu'après tous ces terribles événemens l'armée de Mack a dù être réduite à 40,000 hommes tout-au-plus, 25 mille ayant été perdus dans 
les différens combats, et par l'affaire de Memmingen, et 12 à 15,000 se trouvant avec Jellachich; qu'avec ces 40,000 hommes Mack vouloit tenter l'impossible pour gagner l'armée Austro-Russe (forte environ de 65 mille hommes) qui a dû se mettre en marche le 16 ou le 17 de ce mois; mais que cette jonction ne pouvoit pas se faire sans une espèce de miracle, puisque l'armée françoise avec des forces triples de celles de Mack ne lui aura pas laissé un moment de repos, et $q u$ 'on sait depuis ce matin, que Bonaparte marchoit avec 90,000 hommes pour attaquer l'armée Russe avant qu'elle puisse penser à se réunir à l'autre.

Un revers de fortune aussi subit - car il me seroit difficile, Monsieur, de Vous donner une ilée de la confiance profonde que cette superbe armée de Mack (composée en grande partie de notre meilleure cavallerie!) avoit inspirée à tout le monde, même aux plus incrédules - une révolution aussi suhite doit avoir eu des causes bien efficaces. Mr. de Mack est sans contre-dit un des premiers Généraux qui existent; la célérité, la sagesse, le talent avec lesquels il a, pour ainsi dire, créé deux grandes armées dans l'espace de quatre ou cinq mois, et changé par-là de fonden-comble le systême de la cour de Vienne, et, ce qui étoit beaucoup plus difficile, la direction de l'opinion publique, les plans savans qu' on lui attribuoit, le secret qu'il avoit si admirablement su garder sur toutes ses opérations préalables - tout cela l'avoit rendu pour quelques momens l'idole du pays et le premier homme de la Monarchie Autrichienne. Comment duns si peu de tems tout cela a-t-il pu être détruit? Je m'en vais entrer dans quelques explications sur cette question.

La première source, la cause fondamentale de nos malheurs a été la disproportion entre l'armée d'Allemagne et celle d'Italie, et la trop grande foiblesse de la première. Cette disproportion, on doit bien le dire, étoit la faute de Mack, et elle étoit uniquement celle de son caractère non pas celle de ses calculs. Lorsqu'au mois d'Avril et de Mai on commençoit a former de grands projets à Vienne, il étoit beaucoup plus vraisemblable, que la guerre commenceroit en Italie, et e' est pourquoi on rassembla sur cette frontière les premières forces et les plus nombreuses. Arrivés au mois de Juillet nous pouvions facilement nous appercevoir que Bonaparte nous ayant laissé le tems de former une armée de 250,000 hommes, le seul parti qui lui restoit à prendre étoit celui de nous attaquer en Allemagne. Il ne falloit pas être grand sorcier pour se convaincre que ses armées de Boulogne arriveroient plutôt à Strasbourg qu'à Verone, et au surplus il l'avoit annoncé dès sa première déclaration à la diète de Ratisbonne. Mack le sut et le sentit comme les autres. Mais depuis qu'il avoit fait donner le commındement de l'Arnée d'Italie à l'Archiduc Charles il n'avoit jamais pu se résoudre à proposer sérieusement la diminution de cette armée. Ceci tient au caractère trop conciliant, trop accommodant de $\mathrm{Mr}$. de Mack, et à la mésintelligence à jamais déplorable, qui s'étoit établie entre l'Archiduc et lui. L'Archiduc (sans aucun motif raisonnable et guidé en ceci comme en beaucoup d'autres choses par l'influence de quelques petits esprits qui l'entourent) lui avoit voué depuis sa dernière élévation une haine acharnée, Mack s'étoit fait un principe de désarmer cette haine; il a poussé beaucoup trop loin, et payé bien cher la foiblesse de cette conduite. Aưlieu de déclarer hautement (comme 
ses meilleurs amis le vouloient) que l'armée d'Allemagne devoit avoir 40,000 hommes de plus, et celle d'Italie 40,000 de moins, et au-lieu d'insister sur cette proportion à laquelle le salut de l'état étoit attaché, la bonté de son coeur a faussé toutes ses démarches, et plutôt que de faire ce que l'Archiduc auroit pu cruire une hostilité personnelle contre lui, il seroit allé vers le Rhin avec 30 mille hommes.

A près cette faute capitale ce qu'il $y$ a de plus surprenant dans la conduite de Mack, c'est la position avancée qu'il a cru devoir chuisir. Il savoit avec certitude, ce que nous savions tous, qu'il auroit contre lui toutes les forces de la France avant qu' un seui Russe pourroit le joindre dans cette position. Il vous est connu, Monsieur, par quels artifices nous avions trompé Bonaparte sur nos véritables intentions, et avec quel bonheur nous $\mathrm{y}$ avions réussi jusqu' au commencement du mois d'Aout. Cependant $\mathrm{M}^{\mathrm{r}}$. de Novosilzoff ayant renvoyé ses passeports le 16 Juillet, et les mouvemens de notre armée se développant de jour-en-jour, il étoit clair, que tout ce que nous pouvions espérer encore, c'étoit d'endormir Bonaparte jusqu'à la fin d'A out. C'étıit le maximum de nos espérunces. Or, connoissant la rapidité des opérations militaires des François, nous ne pouvions pas nous dissimuler, que quand même l'armée de Boulogne ne se mettroit en marche que dans les derniers jours d' Aout, elle seroit entre Mayence et Strashourg à la fin de septembre. D'un autre côté nous savions positivement, que la première Armée Russe ne pouvoit dans aucun cas être rendue sur les bords de l'Inn avant le 15 Octobre. Donc, il en résultoit que pendant les deux premières semaines du mois d'Octobre l'armée de Mack se trouveroit seule aux prises arec les François. Voilà, je Vous le jure, ce qu'il y a quatre semaines a été préva, et montré au doigt, dans une petite réunion d'hommes instruits, à lnquelle je me trouvois associé; voilà ce que j'ai moi-même, quoique profane en science milituire, exposé à $\mathbf{M}^{\mathrm{r}}$. de Colientzl le 15 de septembre ${ }^{1}$ ), et dont il est convenu avec moi, et voilà exactement ce qui est arrivé!

Si Mack, au-lieu de s'établir sur l'Iller étoit resté avec toute son urmée sur la frontière de la Monarchie, s'il avoit pris par exemple une position sur l'Inn, voici les avantages majeurs qui en seroient résultés:

1. Il falloit aux François quinze jours de plus pour l'attendre, et aux Russes quinze jours de mnins pour le joindre, ce qui fesoit un gain clair et net de quatre semaines.

2. Si, réuni à la prenière armée Russe, et fort par là de 140,000 il attendoit les François en Bavière, la victoire lui étoit presqu'assurée, et un revers même n' auroit pas eu des suites décisives. Les François ne pouvoient plus avancer.

3. Par cette même mesure on évitoit le scandale de la défection ouverte et injurieuse de l'Electeur de Bavière. En se tenant sur sa frontière on l'auroit toujours empêché de se déclarer contre nous; et si à la fin les François étoient arrivés, froissés eutre les deux grandes armées, il auroit pris le parti du vainqueur. Si nous les battions une seule fois l'Electeur ne bougeoit plus, toute son armée étoit à nous, tandis

1) Am 14. September hatte die ,grosse Versöhnung zwischen Cobenzl und Gentz stattgefunden. S. Gentz' Tag e bücher I. 41. Fournier a.a. U. S. 177. 
qu'à-présent les 26,0 no hommes qu'il a donnés aux François, et l'irritation générale de son pays contre nous ont été des alliés trop utiles de nos ennrmis.

4. Le seul inconvénient auquel ce plan nous exposoit, c'étoit de falloir livrer pendant quatre ou six semaines aux François la Souabe, une partie de la Franconie, et une partie de la Bavière. Mais tout bien considéré cet inconvénient imaginaire étoit plutôt un avantage pour nous. Il est bien triste pour un Allemand sincèrement attaché á sa patrie de faire un aveu pareil; mais comment le dissimuler lorsque les faits les. plus éclatans en déposent? Les Electeurs de Wurtemberg, de Bade et de Bavière sont des traitres qu'il faut abandonner au mépris et à la vengeance publique. Toute rette partie de l'Allemagne, une des meilleures pour les dispositions individuelles des peuples, a été tellement dépravée par ses Princes, que notre seul espoir devoit etre de la voir ramenée au bien par l'escès de son propre délire; et si les François l'avoient ravagée sans miséricorde, c'étoit, il faut le dire, un des grands services qu'ils pouvoient rendre à la cause de notre Monarchie, au salut, ì la conservation de l'Europe.

Un troisième reproche qu'on fait au Général Mack (mais pour celui-ci je crois qu'il faut bien suspendre le jugement, puisque nous ne sommes pas encore en état de décider) c'est d'avoir permis aux François de passer son armée (en traversant le Wurtemberg) colonne par colonne, et de la former derrière lui. Ceci a probablement tenu à la conviction dans laquelle le Général paroit avoir été de maintenir la position d'Ulm jusqùà l'arrivée des Russes; peut-être aussi à des renseignemens fautifs sur ce qui se passoit plus loin. Mack a eu devant lui les colonnes de Ney, de Lannes commandées immédiatement par Bonaparte; il a bien su que Bernadotte et Marmont s'étoient portés de Mayence par Aschaffenburg sur Wurtsbourg; mais on croit, on craint, qu'il n'a pas assez bien connu la force de cette armée, qu'on s'est opiniatré à appeller un corps d'observation, tandis qu'elle étoit tout-de-bon l'aile gauche de la grande Armée Françoise. Une autre circonstance sur laquelle il ne pouvoit pas crimpter, c'est que cette Armée, renforcée par les Bavarois prendroit le chemin d'Anspach, circonstance funeste, (mais, si Dieu ne nous abandonne pas, plus funeste, j'espère, aux François, par ses effets futurs) qui a infiniment raccourci la marche des Généraux François, les a mis en état de passer le Danube entre le 7 et le 9, et réuni toutes les forces françoises sur le Lech avant le 11.

Enfin, quelque soit le dénouement final, on ne peut pas le dissimuler, le premier acte est fini. Si Mack a le bonheur de se faire jour avec les restes de son armée, et de gagner celle des Russes (dont l'avantgarde, commandée par $\mathbf{M r}$. de Meerveld, et le centre par Mr. Kutusoff feront certainement ce que des hommes peuvent faire) il peut mettre une barrière aux François; mais il ne les repoussera plus au delà du Rhin dans cette campagne. Si au contraire Mack continue d'être malheureux, s'il ne peut pas se joindre à l'armée Russe, s'il est obligé de chercher la frontière de la Bohème, si l'armée Russe, trop foible pour lutter seule contre les François, doit se replier à son tour, certes, nous devons nous préparer à de grands désastres. Nos affuires pourroient se rétablir sur- 
le-champ, si nous avions à-présent à notre disposition cette seconde armée Russe, plus forte que la première, qui se traine par les états l'russiens. Si cette armée se trouroit aujourd'hui a Egra, e'est elle que Mack iroit joindre, et dans trois jours il pourroit reprendre l'offensive. Ft pourquoi ne jouissons nous pas de cette ressource immense? Hélas, il faut bien le dire; puisqu'une poignée d'ignorans et de mauvaises têtes avoient formé le projet détestable, le projet insensé de forcer le Roi de Prusse dans la coalition. Si au-lieu de camper pendant deux mois sur la frontière de Prusse, (pour entrainer le Roi!!) cette armée avoit suivi la premeière ${ }^{1}$ ), si, pendant que celle-ci se rendoit par $B$ rünn à $L$ inz et l'autre s'étoit partie par Ollmutz sur la Bohème, nous aurions aujourd'bui 120,000 hommes, qui joints à nos forces dispersées, mais non pas anéanties, nous donneroient 200,000 hommes d'excellentes troupes à opposer aux François. L'extravagance de $\mathbf{M r}^{\mathbf{r}}$. de Wintzingerode ${ }^{2}$ ) (un des hommes qui dans ces derniers tems ont fait le plus de mal à l'Europe) la bétise de deux personnes à Vienne qu'il avoit gagnées pour ses misérables projets, enfin, il m'en coute de le dire, mais encore la foiblesse de Mack, qui auroit $d \hat{u}$, qui auroit $p u$ pulveriser ce plan (qui m'a avoué au commencenment d'Aout qu'il n'y comptoit pas beaucoup) ont tout perilu. Quel bonheur encore que des événemens imprévus aient contrebalancé l'effet de cette faute impardonnable, et que de-moins le Roi de Prusse, s'il me se joint pas à nous de coeur et d'ame, ne nous combattra pas non plus, chose que nous risquons évilemment, dont $\mathrm{Mr}^{\mathrm{r}}$. de Wintzingerode se moquoit, et qui n'en auroit pas moins livré dans trois mois tout le continent, pieds-et-poings ${ }^{3}$ ) liés à l'exécrable tyrannie de la France! - Cette idée fait dresser les cheveux.

Maintenant il s'agit de savoir, quel parti on peut tirer des circonstances embarassantes mais non pas désespérées dans lesquelles nous nous trouvons. Voici quelquesunes de mes idées; dans un moment pareil je crois m'acquitter d'un devoir sacré en Vous les communiquant sans méthode ni parure quelconque.

1. Avant-tout il ne faut pas perdre la tête. - J'espère que ce malheur là ne nous arrivera pas, et je compte sur-tout extrêmement sur le sangfroid, la fermeté, et les sentimens honorables dont l' Empereur de Russie a fait preuve depuis quelques mois. Les choses remarquables qu'il vient de dire au Prince d'Auersperg 4), son voyage à Berlin, celui qu'il va faire à Vienne, la confiance qu' il inspire par-tuut, nous encourageront et nous soutiendront. Les dispositions personnelles de l'Empereur d'Allemagne sont excellentes. Il ne succombera pas de si-tôt au découragement; et ses Ministres, quelques foibles qu' ils soient, ayant une fois pris le parti

1) Ms. seconde.

2) Der russische General Ferdinand von Wintzingerode (1770-1818) S. Al l'g. D e u t $\mathrm{s}$ ch e B i og raph i e 43,503 und über seine diplomatische Thätig. keit im Jahre 1805 die Werke von Beer, Fournier, Wertheimer. Wie schlecht Gentz über vieles unterrichtet war, hat namentlich Yournier S. $177 \mathrm{ff}$. nachgewiesen.

3) Ms poinds.

4) Ich muss es österreichischen Forschern, denen bessere Hilfsmittel zu Gebote stehen als mir, überlassen, diese Anspielung zu erklären. Die Allg. Deutsche Biographie und Wurzbach: Biogr. Lexikondes Kaiser. thums Oesterreich lassen im Stich. 
de se révolter contre l'oppresseur commun, ne peuvent pas reculer sans se noyer dans la honte. L'opinion publique est équivoque; elle étoit aux nues avant l'ouverture de la campagne, elle tombe à vue d'oeil après les premiers revers; il faut donc la soutenir; et si je pouvois vous exposer tont ce que j'ai fait pour ma foihle part dans cette partie essentielle, vous me fériez l' honneur de Vous livrer avec moi à l' espoir d' un triomphe final.

2. Il faut tout-de-suite refaire l'armée. Nous avons, supposé même que Mack n'ait plus que trente-cinq mille hommes, lorsqu'il arrivera au port, nous avons dis-je 65,000 bommes sur l'Inn; s'ils se replient, nous ne les perdons pas; s' ils sont battus il en restera toujours entre 40 et 50 mille. Avec les corps de réserve qui se forment, et dont on doit accélérer l' organisation, avee 20 mille hommes que la diète de Hongrie vient de nous promettre (o utre la levée en masse de $50^{\mathrm{m}}$ ) pour compléter l'armée, et lesquels, a-la-vérité ne devoient être disponibles que dans trois mois, mais qu'il faut demander, presser, sur-le-champ il sera très-possible de former dans six semaines peut-être plu'ôt une nouvelle armée de 120,0110 hommes sur nos frontières. Si avec cela on parvient à accélerer la marche de la seconde armée Russe; nous aurons de ce côté-là encore 70 ou $80^{\mathrm{m}}$ hommes, plêts à tout entreprendre. Si nous empêchons les François d' entrer dans les pays héréditaires, ou du-moins d'y faire des progrès, nous pouvons dans moins de deux mois reprendre l'offensive en Allemagne. Mais il ne faut pas perdre un instant.

3. Il faut que l'Archiduc Charles frappe quelque grand coup en Italie. - Il est bien déplorable que cette armée dont la supériorité etoit si évidente, $n$ 'ait pas commencé ses opérations depuis quatre semaines. Mais l'Archiduc, secrètement mécontent et irrité (- parcequ' on s' est décidé à la guerre malgré lui - parcequ' il désapprouve tout ce que Mack entreprend - parceque sa haine et sa jalousie contre celui-ci l'emportoient sur toute autre consideration) n' a pas montré jusqu' à présent cette énergie qu' on lui connoissoit autrefois, et il est de plus extrêmement mal entouré ' $)$." Il a auprès de lui d' excellens généraux, mais aucun, du-moins aucun parmi les principanx, qui ait l' esprit entreprenant et l'âme active; ce sont tous des calculateurs et des tacticiens, comme Bellegarile ${ }^{2}$ ), Jack [?], Grünne ${ }^{3}$ ) etc. ou bien - ce sont les derniers des hommes comme les Aides-de-Camp de l'Archiduc. - Dans le moment actuel il n'est pas même à désirer que l'armée d'Italie fasse de trop grands progrès; après ce qui est arrivé en Allemagne elle ne peut et elle ne doit pas trop s'avancer. Mais ce qui est infiniment désirable, et même invispensable, e'est que d'abord par quelque action éclatante l'opinion publique soit relevée; ensuite que l'Archiduc passant le Mincio, investissant Mantoue, et tournant le lac de Garda prenne une position moyennant laquelle toutes les entrées du Tyrol restent à sa disposition, pour menacer en cas-de-besoin l'armée Françoise

1) Vgl. Wertheimer a. a. O. I. 311 , Nichts wäre irrthümlicher, als den italienischen Feldzug Erzherzog Karls nach den Briefen von Gentz zu beurtheilen ${ }^{\circ}$.

2) Heinrich Graf von Bellegarde (17:6-18t6) hatte rühmlichen Antheil an der Schlacht ron Caldiero, s. Allg. De utsche Bıographie ․, 305.

3) Philipp Grünne, Graf von Piı,chard (1762-1854), 1805 Referent des obersten Chefi des Kriegswesens, s. Allg. Deutsche Biographie 10,55. 
en Allemagne d'une diversion de ce côté-là. - Il a dù commencer ses opérations le 16, jusqu'aujourd' hui on n' en a aucune nouvelle.

4. Enfin, il taut certainement ne rien négliger pour cultiver les bonnes intentions dans lesquelles la Prusse paroit se trouver depuis quel ${ }_{\text {ques }}$ semaines. Cependunt, permettez-moi, Monsieur, de Vous exposer encore sur ce point quelques-unes de mes ilées; elles peuvent se ressentir de la crise du moment, elles peuvent être' erronnées; mais dans tous les cas je arois $q u ' e l l e s$ méritent votre attention.

Depuis que je suis à Vienne je n' ai fait jour et nuit que prêcher la nécessité d' une alliance avec la Prusse. Tout ce que j'ai adressé à votre gouvernement de lettres et de mémoires depuis trois ans, en fait foi; et je regarderai toujours comme une erreur fondamentale, et peut être irréparable d'avoir entamé une nouvelle guerre contre Bonaparte sans s'être préalablemant assuré de la Prusse. Je pourrois écrire un livre sur les causes de cette funeste méprise; car je les connois toutes; mais il n' en est pas question à présent.

Je serai llonc certainement le dernier homme à combattre ce qui peut consolider une liaison intime entre Vienne et Berlin. Muis je dois Vous le confier, depuis quelques semaines il se réalise chez nous ce que le poëte a dit dans son tems:

Dum vitant . . vitia, in contraria currunt! Non-content de recevoir avec reconnaissance les premières ouvertures de la cour de la Prusse, de la flatter, de la cajoler, de la rechercher - tout cela est bon et sage - on lui parle comme si notre salut, et notre existence étoit irrévocallement lié à ses résolutions, et le langage qu' on lui tient depuis les revers sur le Danube, est tout aussi impolitique qu'il est indécent et indigne d'une grande puissance. On vient de la conjurer de faire entrer ses troupes en Bohème. Cette démarche est fausse et pernicieuse au-delà de tout ce qu' on peut imaginer. Elle produira d'abord sur l'opinion publi jue de notre pays un effet qu' on ne peut calculer que quand on connoit ce pays. Elle amenera de plus, comptez-y, Monsieur, dans moins de trois mois un relroidissement, une jalousie mutuelle, une brouillerie complète entre les deux puissances. Non! Non! C' est comme auxiliaire et non pas comme protecteur que le Roi de Prusse doit intervenir dans cette guerre. Dès qu' il ne peut pas agir de son côté, et tout-à-fait isolé des armées Autrichiennes l'oljet principal est perdu. Déjà tout amalgame entre des troupes Autrichiennes et Prussiennes est le comble de la mauvaise politique. Ces troupes ne peuvent jamais agir ensemble; tout s'y oppose. Battus avec nous, ils nous en imputeront le tort; victorieux avec eux, nous-voulrons leur en enlever le mérite. Le repentir le plus amer succédera au desir momentané de se voir soulagé dans une grande crise; l'Autriche sera peut-être sauve pour six mois; mais l'Allemagne, mais l' Europe sera perdue pour toujonrs.

S'il m'est permis d'ajouter à tout ce que je viens de dire quelques réflexions sur ce que je crois dans ce moment-ci être la vraie politique du Gouvernement Anlgois, qui doit toujours tenir la balance entre les grandes cours $d u$ continent, voici ce que je proposerois:

Je crois d'abord, et je compte assez sur la générosité et sur la magnanimité de Votre Ministère pour ne pas même en douter, que vous devez tout faire pour encourager et soutenir la Cour de Vienne dans ses premiers 
revers; non seulement qu'il me paroit essentiel que vos négnciations pécuniaires ne se ressentent le moins du monde de rien qui pourroit indiquer de la défiance ou des craintes, je crois encore que quelque déclaration formelle, soit qu'elle se fasse à Lonilres ou ici, quelque note solemnelle, dans laquelle en rappellant les grands objets de cette guerre, vous écarteriez toute idée de découragement, de pusillanimité, d'abandon, en exprimant laconfiance, que vous avez dans la fermeté inébranlahle de l' Empereur, fervit dans l'epoque où nous sommes un bien infini. Je sais que cela produiruit un grand effet; et si la chose n'étoit pas trop contraire aux formes établies dans Votre cabinet ce seroit ici le cas, où une lettre adressée par Sa Majesté le Roi lui-même à l' Empereur seroit d'un avantage incalculable. La cour de Vienne, vous le croyez comme moi, duii toujours être la base et le centre de toutes les graniles entreprises contre la France; il est donc de toute nécessité que cette cour ne foiblisse pas, et il faut saisir tous les moyens imaginables pour détourner un malheur pareil.

Ensuite il me paroit nécessaire, que vous éclairiez l'Autriche sur ses véritables intérèts par-rıpport à la Prusse. Tout en insistant sur la nécessité de gagner et de conserver la Prusse, au prix même de beaucoup de sacrifices, vous devez empêcher, par les raisons que je viens de Vous soumettre, que la cour de Vienne ne se jette pas aveuglement entre ses bras; vous devez suns cesse faire sentir à la cour de Vienne que ses forces bien organisées, et réunies à celles de la Russie suffisent et doivent sulfire pour la défense de ses pays héréditaires et de tout le midi de l'Allemagne, et que toutes les furces de la Prusse doivent être concentrées pour opérer la grande diversion, la seule puissante et décisive, l'attaque des Pays-Bas et de la Hollande. Si les forces Prussiennes sont éparpillées en Franconie, en Bohème, sur la frontière de la Bavière, ou même en Westphalie, nous nous soutien/rons pour quelques mois par des opérations bien-combinées mais nous finirons par périr tous ensemble. Que l'armée Prussienne se trouve d'ici à quatre semaines devalt $\mathrm{M}$ a estricht, et d'ici à trois mois devant Lille, - personne n'aura à craindre de voir les François devant Vienne.

Je rous demande pardon de la forme crue, et de l'espèce du désordre dans le'juel je vous présente mes réflexions. Je n'ai pas eu le tems de les réliger, et je crois qu' il ne s' agit que de se fuire entendre dans un moment cumme celui-ci. Je me croirois le plus heureux des mortels, si ceux auxquels visus jugerez convenalile de communiquer cette lettre J trouvoient seulement quelques apperçu : justes, et dont on peut tirer parti. - Je publierai dans huit jours un petit ouvrage »sur les relations entre l'Autiche et la Frince depuis la paix de Luneville." C'est un chapitre seulement d'un travail plus éten'lu que je ferai paroitre cet hiver sur l'éłuilibre politique de l'Europe" et dans lequel je me propose aussi de traiter à-lon l lia question de ce qui est proprement l'intérêt de l' Europe dans la guerre entre l' Angleterre et la France ${ }^{1}$ ). J'en ai détiché le chapitre sus-dit, puisqu'il faut frupper vite, et puisque c'est celui qui in-

1), Fratgmente aus der nenesten Geschichte des politischen Gleichgewichtes in Europa* Petersburg (Leipzig) 1806. 
fluera le plus sur l' opinion de ce pays. Aussitôt qn' il sera imprimé j' aurai l' honneur de vous l'adresser.

Je Vous prie, Monsieur, et très-particulièrement, de m'annoncer le plutôt possible la réception de cette lettre: Vous sentez bien, que pour soutenir mon courage et mon activité, il faut que je sache toujours, que vous accueillez mes idées et que Vous les trouvez bonnes à quelque chose. Trois lignes écrites dans ce sens, et je ne vous en demande pas d'avantage, m'animeront plus que tous les encouragemens que je puis trouver autour de moi. La manière infiniment honorable dont on a purlé l'autre jour dans le Morning-Port d' un de mes mémoires de l'année dernière, et la traduction excellente qu' on $\mathrm{y}$ avoit fait de quelques passages de ce mémoire, m'ont prouvé de-nouveau, que quelques peines qu' on éprouve quand on a toujours à combattre les opinions perverses du continent, on ne fuit jamais un taux calcul en comptant sur les suffrages de votre admirable pays.

Je vous prie d'agréer l'hommage da dévouement invariable avec lequel j'ai l' honneur d'être,

\section{Monsiour \\ Votre très humble et très fidèle serviteur Gentz.}

P. S. Vous parler dans ce moment d'affaires particulières me pèse sur l'amø. Excusez-moi donc par l' extrême nécessite. Je ne vous demande pas un nouveau secours immédiat; mais comme je ne puis pas supposer que votre gouvernement me retirera jamais les siens, je vous supplie seulement de promettre à Mr. Coutts ${ }^{1}$ ) pour un tems indéfini, muis cependant de manière à lui inspirer de la confiance, que ce que je pourrai tirer sur lui jusq'à concurrence de 6 ou 800 L. St. sera remboursé. La situation, où nous nous trouvons ici est telle que d' un jour à l'autre l'ennemi peut se touver à notre porte. Mon nom est inscrit à la première page du livre des destinées de ces scélérats. Je crois qu'il n'est pas bien loin du votre (quoique leur extrême ignorance les ait fait l' autre jour confondre celui-ci avec celui de M. A. S. Hammond controlleur de la marine) ${ }^{2}$ ) et vous sentez bien, que comme ma personne est tout mon bien, je ne puis pas l'exposer à leur vengeance. Je serai donc obligé de décamper parmi les premiers. Dans cette crise terrible il n'y a que la générosité de notre ministère qui puisse me conserver à la chose publique. Agréez donc la demande que je rous fais pour M. Coutts. Alors je serai toujours sans inquiétude, surtout qu'en cas de besoin je pourrai avoir mon recours de ce côté là. J'ai écrit à Coutts de se présenter chez vous à cet effet et ma confiance en vos bontés et celles de Lord Mulgrave auquel je vous prie de présenter mes très humbles hommages est trop illimitée pour [que] ${ }^{3}$ ) je craigne que vous lui donniez un refus.

1) S. o. S. 109 Anm. 5.

2) Andrew Snape Hammond (1738-1828). S. Dictionary of National Biograph y $X \lambda I V .251$.

s) que fehlt im Ms. 
VII.

\section{Gentz an Hammond ${ }^{1}$ ).}

Vienne le 1 Novembre. [1805]

Monsieur !

Lorsque j'ai eu l'honneur de Vous adresser ma lettre du 23, il manquoit encore le dernier complément à nos malheurs. Vous savez à présent quel en a été le terrible denoûement.

Connoissant d'ancienne date l'extrême foiblesse de ceux qui sont à-la-tête de l'administration de ce pays, Vous pouvez aisément vous figurer l' excès de consternation et d'embarras qui règne ici. C' est bien moins le désespoir de voir ruinée la plus belle des causes, de voir ee premier grand effort vers la délivrance de l'Europe honteusement échoué, et le pouvoir de la France raffermi et augmenté au-lieu d'être ebranlé, e' est bien moins cette douleux noble et élevée, que la crainte, platte et vulgaire de l'arrivée des François à Vienne, et mille considérations particulières, toutes plus mesquines les unes que les autres, qui les occupent.

Si leurs dispositions actuelles $\mathbf{n}$ 'étoient pas liées directement à la destinée future de l'Europe, on se contenteroit de les plaindre, et de les abandonner à leur misère. Mais il ne laut pas se le dissimuler; c' est ici l'avant-dernier acte de la destruction finale de l'Europe. Si l'Autriche succombe cette fois-ci, le continent est à-jamais paralysé et asservi, et la seule question qui reste est celle du tems qu' il faudra aux François pour écraser impunément l' Angleterre.

Il est donc de la plus haute, de la plus extrème importance d'obvier a un malbeur qui entraineroit après lui tout ce que l'imagination peut concevoir de plus déplorable. L' examen des moyens par lesquels l'Autriche peut ètre préservée du désespoir est dans ce moment-ci le plus grand objet de toute la sphère politique; et chaque cabinet doit entrer dans cet examen à l' exclusion même de toute autre affaire quelconque, jusqu'à ce que l'on soit arrivé à quelque résultat satisfaisant.

Si la cour de Vienne possédoit l'énergie et les talens qui lui manquent, elle trouveroit encore dans ses prupres forces, et dans sa situation politique tout ce qu' il lui faut pour se relever après les désastres qu' elle a éprouvés.

Ses forces sont loin d' être épuisées; sa situation politique est meilleure qu' elle ne l'a été depuis quinze ans. Elle a encore 100 mille hommes, en Italie, 40 mille dans le Tyrol, 20 mille sur l'Inn qui forment avec les Russes une armée de 60 à 70 mille hommes; indépendamment des débris de l'armée détruite, des reserves, de la levée en masse en Hongrie. Si l'Archiduc Charles commençoit par battre Massena et assez vigoureusement, pour que celui-ci ne pat pas. du-moins en quatre semaines. penser à une expédition contre les provinces de l'Intérieur, si après cela il se réunissoit à l' armée du Tyrol, se portoit par des marches forçeees sur Salzbourg (point central de toutes nos opérations) et agissoit de concert avec l'armée Austro-Russe, nul doute, que dans moins de quatre semaines il

1) Die Adresse fehlt, ergiebt sir h aber aus dem Verweise auf den Brief rom 23. Okt. Vgl. die Briefe an Starhemberg und J. von Müller vom 3. Nov. 1805 a. a. O. S. 125 und S. 128. 
pourroit purger l'Allemagne de la présence des François. On n' est pas aux abois, quand on a encore des moyens pareils à sa dispnsition.

Mais l'Archiduc Charles n' en fera rien. J'ai eu tr'p souvent l'occasion de vous le peindre pour revenir ici sur son portrait. Je ne sais pas si dans une autre guerre, si sous des circonstances tout-à.fait différentes, il reprendroit encore une fois le caractère qu' il a montré pendant un petit nombre de momens brillans dans sa vie. Nais ce qui est indubitable c' est qu' il ne le déploira pas rans la guerre actuelle. Il est outré contre les Ministres qui ont appelé Mark, contre l'Empereur qui l'a protégé, contre la guerre, qu' il a constamment désapprouvée, contre les Russes, qu'il a toujours eus en horreur, contre tous les projets, contre tous les arrangemens, contre toutes les mesures militaires et politiques puisqu' il les regarde uniquement comme l'ouvrage de ses ennemis. Les François ont passé l'Adige; il a essuyé un échec le 24, qui lui a couté 1700 hommes, et 7 à 8 canons; il se repliera, il arrivera à Vienne. il prêtchera la paix, il la signera, - n'en doutez point - si on ne change pas de fond-en-comble l' état des choses. Il se jettera avec son armée sur lu Styrie, en attendant les François disposeront de l'armée du Tyrol, puis de l'armée Austro-Russe, puis de la sienne.

Il en est de même de la situation politique de l'Autriche. Sûre de l'alliance de la Russie et de l'Angleterre, et voyant que la Prusse, loin de travailler contr' elle, fait des voeux pour sa cause, et fera dans tous les cas quelques efforts pour la soulıger, il est clair qu' elle se trouve placée sur une base magnificue, et que sa position fondamentale est meilleure qu' elle ne l'a été depuis longtemps. Mais les Ministres n' ont plus d'yeux pour voir l'ensemble de cette position; ils ne s'arrêtent qu'aux détails. Il est done de toute nécessité de les rapeler sans cesse au grand ubjet de cette guerre, qui n'a pas été résolue pour defendre la, fruntière contre un ennemi qui l'eut menacé directenient, mais pour changer un état de choses avec lequel il n'y aurcit plus rien eu à défendre dans deux ou trois ans. Le Ministère Autrichien a déjà commis la faute cupitale de dénaturer le caractère de cette guerre dans plusieurs de ses premières démarches, en faisant naitre l' idée qu' elle la regardoit comme une guerre défensive; il faut tout faire pour empêcher que cette funeste méprise ne s'étende pas plus loin.

Tous les yeux sont fixés à-présent sur la détermination finale du Cahinet de Berlin. Elle duit nous être connue dans peu de jours; e' est elle qui décidera du sort de cette guerre. Si le Roi de Prusse se déclure pour les Alliés sans restriction ni modification, nul dunte, que le Cabinet de Vienne, malgré sa foiblesse et sa consternation ne se suutienne cette fois-ci au-milieu de la tempête. Jusqu'ici le langage de ce calinet est heureusement resté le même; la première ouverture de paix. faite par Bon:p prte lui-mème au Général Mack après les événemens d' Ulm ${ }^{1}$ ), vient d'être déclinée; la liaison intime de l'Enpereur avec le Souvrain de la Russie sera toujoars une forte larrière contre les accès de pusillinnimité et de découragement; et si la Prusse se déclare, je garantis qu'il ne sera pas question d'un changement total de systême dans les premiers six mois.

1) Vgl. Wertheimer a. a. O. I. 305. 
Le seul danger qui nous menacera alors sera celui qui nous viendra de la Prusse elle-même, puisque cette puissance, en la supposant même monte au plus baut dégré de vigueur qu'elle puisse atteindre, n' en aura jumais assez pour no pas mêler des propositions pacifiques parmi les opérations de la guerre même la plus active.

Mais si la Prusse ne venoit pas à notre secours d' une manière bien décisive, ou si seulement elle se contentoit de nous soulager momentanément pur quelque démonstration sérieuse du côté de la Franconie, en se réservant de confier le reste au succès de quelque médi،tion ou négcciation avec la France, dans ce cas-là, Monsieur, je ne balancerai pas un instunt à regarder comme un événement jmmanquable la conclusion de quelque paix juneste avant la fin de l'hiver. Je dis, que je regarderai alurs cet événement comme immanquable, à-moins qu'on ne trouve de noureaux moyens, et des moyens bien efficaces pour contre-bulancer les canses qui le produiront.

Encore une fois: La recherche de ces moyens est devenue la plus grande affaire des cabinets de l' Europe. On se refait après les plus territles revers; les armées détruites renaissent dans un pays, dunt les ressources sont immenses; une campagne heureuse fait oublier tous les malheurs précédens; mais lorsque l'esprit d'un gouvernement est tué, il n'y a plus d'espoir; et si ce malheur arrive cette fois-ci à l' Aulriche, elle est morte sans espoir de résurrection, et toute l' Europe avec elle.

Permettez-moi done de Vous exposer ici ce que je crois que Votre Gouvernement pourroit faire dans une crise, où vos démarches doivent aussi essentiellement influer sur le sort de la cause commune. Les mesures que je $m^{\prime}$ en vais Vous présenter, ne seront peut-être pas toutes de nature à être exécutées: elles rencontreroirnt peut-être chez Vous des olistacles que je ne puis pas juger à la distance où je me trouve. C'est à Yous certainement à prononcer sur mes propositiuns. Mais je crois rendre un des services les plus essentiels à la cause commune, en vous les soumettant telles que je les crois conformes à la position des choses ici; et comme d'un côté je connois aussi exactement que qui que ce soit les intérêts et les liesoins de la Cour de Vienne, et que d'un autre côté mes sentimens pour l'Angleterre sont trop connus pour que je puisse jamais étre accusé de vouloir sacrifier ses intérêts à un but étranger quel.onque, je we flatte de réunir en m: personne tout ce qui peut me rendre digne d'être écouté de Vous dans cette occasion solemnelle.

Je cruis que les mesures par lesquelles l' Angleterre doit venir au seours de l'Autriche sont de trois espères différntes; mesures de procédés; mesures militaires; mesures politiques.

J'appelle mesure de procédé tout ce qui dans ce moment pénible peut s'adresser aux sentimens personnels de l'Empereur et des prinı.ip.ux Ministres. I'éjà duns ma lettre précédente j' ai riris la lilierté de tou.her cet objet; je suis plus que jamais persuadé de l'excellent eff.t, que produiroient des mesures purrilles. Je place toujours à-la-tête de tout une lettre que Sa Majesté le Roi écriroit à l'Empereur, liapuelle (si des objections à moi inıonnues ne rendent cette résolution in practionlle), serrit d'autant plus efficace que cette démirrhe est moins dins les bil itudes de Votre Auguste Souverain, et que par cela même elle trupperoit extrême- 
ment. II faudroit ensuite ajouter aux communications verbales de Votre Ministre des notes rédigées d'aprés vos instructions pärticulières, et présentant à cette cour la nature et les objets de la guerre dans toute la clarté et dans toute la force que Vos hommes d'état sont si éminemment capables de porter dans des représentations pareilles. Enfin je crois aussi, que si Mr. Paget 1) étoit revêtu dans ce moment même du caractère d'Ambassadeur, outre le poids et l'éclat que cela ajouteroit à ses négociations, la résolution en elle-même, et le choix de l'époque seroient singulièrement propres à montrer à la cour de Vienne, quel intérêt constant Vous attachez à tout ce que peut la relever et la soutenir.

Quant aux mesures militaires, il ne me conviendroit certainement pas d'entrer dans aucun détail sur celles que je crois les plus convenables à nos besoins et intérèts actuels. Mais ce n' est aussi pas sous ce pointde-vue là que je veux envisager cet objet. Il me suffit de vous assurer en général, qu'une expédition quelconque, que l'arrivée d' une Armée Angloise sur quelque point du continent que ce soit en France, en Hollande, en Allemagne, en Italie, seroit un avantage incalculable dans les circonstances actuelles. Outre la diversion réelle qu' elle opéreroit, elle frapperoit l' opinion publique de la manière la plus éclatante et la plus salutuire. Réunis aux forces de la Prusse, ou, si celle-ci ne s'engageoit pas aussi loin, de la Russie et de la Suède, un corps Anglois de trentemille hommes pourroit dans ce moment-ci changer la face de l'Europe. Car si, perdant que l'armée principale de Bonaparte (sa seule armée active et proprement disponible) est occupée dans le Midi de l'Allemagne, 60 mille hommes se portent sur les revers de la Hollande, tandis que 30 mille Anglois débarquent sur la côte, ou bien le ciel a juré la perte de l'Europe, ou la Hollande est perdue pour la France, et la principale frontière de celle-ci entamée clans moins de deux mois. Mais il n'y a pas une heure à perdre.

Enfin, les mesures politiques se réduisent maintenant toutes à une seule. Je suppose que vos relations avec la Russie et que les dispositions personnelles du Cabinet de Petersbourg sont telles, que de ce côté-la il n' y a plus ni crainte ni incertitude. La Cour de Vienne ne peut pas bouger, et ne bougera pas, si la conluite de la Prusse ne lui en offre le motif ou le prétexte. C'est donc la Prusse qu' il faut travailler sans relâche mais je crois que le moment est venu, où il faut la travailler sur une autre base, et sur d'autres principes que tous ceux que l' on a pu suivre jusqu' à présent.

Il est à-la-fin universellement reconnu, que sans le concours complet et constant de la Prusse, la France ne peut pas être renvoyée dans ses anciennes frontières. Cette vérité a été entrevue, développée, prêchée depuis quatre ans par des personnes, dont les lumières ne pouvoient pas être contestées: Il est évident, que si la Russie se déterminoit même à mettre en-campagne 400 mille hommes de ses troupes, et de les joindre à toutes les forces de l'Autriche, cette masse ne suffiroit pas pour atteindre le grand objet de toute réunion raisonnable contre la France. La puissance colossale de celle-ci ne sauroit être vaincue si elle n'est pas attaquée simul-

i) S. o. S. 116, Anm. 1. 
tanément sur ses deux flancs. Or, les forces de la Russie seront tout ce que l' on voudra; leur direction ne convient pas à la grande entreprise. Ces forces sont toujours placées derrière celles de l'Autriche; c' est par l'Autriche, c'est-à-travers ses pays, que les Russes peuvent seuls atteindre la France; car si même ils envoyoient une armée de cent-mille hommes contre la Hollande, et que la Prusse leur permit de le faire, dèsque celle-ci n'agit pas positivement avec elle, cette armée, séparée toutà-fait du corps de l'Empire ne peut pas se soutenir long-tems. C' est toujours sur la ligne des possessions Autrichiennes que les forces Russes doivent attaquer la France, et il en résulte que toute Armée Russe ne sera jamais qu' une Armée Auxiliaire, dont tout l'avantage consiste à dispenser la maison d'Autriche de lever autant de troupes de plus sur son propre territoire.

Mais la Prusse est la seule des grandes puissances dont les forces soient placées de manière à ce qu' elles peuvent directement concourir au but. Ia direction des forces Prussiennes est précisément ce qu'il faut à I' Europe pour atlaquer la France avec succès. Si, pendant que l'Autriche et la Russie opèrent en Italie, en Suisse, et dans le midi de l' Allemagne, le Roi de Prusse, secondé par l'Angleterre, et en cas-de-besoin par la Suède et le Danemark, se porte avec 150 mille hommes sur le Bas-Rhin, attaque les places de la Meuse, se rend maitre de Maestricht, ensuite de Breda, de Bergen-op-Zoom etc., prend ainsi la Hollande à-revers, entre dans les Pays-bas, menace l'ancienne frontière de la France, alors mais seulement alors nous avons deux, et avec l'Italie, même trois grands théatres de guerre, et toutes les probabilités se réunissent en notre faveur. Si les François ont du succès d'un côté, les progrès que l'on peut en attendant faire de l'autre les forcent à quitter leur avantage, ou mettent la partie victorieuse en-état de secourir la partie souffrante. Cette même manoeurre (et il n' est pas, Dieu-merci, impossible d'avoir des succès partout) cette manoeurre répétée plusieurs fois doit nécessairement harceler, vexer, et affoiblir la France au-point de modérer finalement la fougue de son activité et de son insolence.

C' est pour avoir méconnu ces vérités, Monsieur, que nous déplorons aujour-d'hui le non-succès de nos premiers efforts. Il est bien triste de falloir le dire; mais cette-fois-ci on pouvoit gagner la Prusse, si on prenoit les mesures indiquées par une infinité de symptômes que l'ineptie des ụns n'a pas vus, et que l'opinatreté des autres n'a pas voulu voir. De misérables préventions ont rendu sourd le Cabinet de Vienne à tout ce qu' on pouvoit lui offrir de plus sage et de plus convaincant sur cet objet.

- Jamais la Prusse ne sortira de l' atmosphère de la France ; - jamais la Prusse ne fera la moindre démarche en notre faveur - elle est irrévocablement perdue pour toute cause commune" — voilà les objections qu' on étoit sans cesse condamné à entendre, et qui déjà-à-présent sont si complètement démenties par ce qui se passe sous nos yeux. A l'époque de ces préventions avoit succédé plus-tard celle de l' aveuglement et d' une confiance téméraire. On croyoit ne plus avoir besoin de la Prusse, puisque la Russie étoit avec nous. Seconde erreur que nous avons payée bien-cher. Mais il en restoit encore une troisième qui nous auroit infailliblement anéantis, si la providence - car les hommes n'y ont été pour 
rien - si la providence n' étoit pas venae à notre secours. C'étoit celle qui nous ait croire que nous pouvions forcer la Prasse.

Il faut tirer le voile sur toutes ces méprises funestes. La cour de Vienne en est cruellement punie, et elle a fait amende honorable. Jamais repentir n' a été plus amer, jamais révolution de systême politique plus rallicale; dans moins de huit jours nous sommes arrivés de l'étoignement le plus décidé à l'abandon le plus entier et le plus illimité; ef lo seule chose qu' on puisse à-présent reprocher à la Cour de Vienne dans ses rapports avec la Prusse e' est d'avoir trop oublié dignité, et peut-être d' avoir compromis ses intérêts futurs, et les intérêts de la cause commune, par la nature et sur-tout par le ton et la couleur des démarches qu' elle vient de faire à Berlin.

Cette résipiscence tardive ne suffira pas pour assigner à la Cour de Prusse le rôle qu'elle doit nécessiirement jouer dans la crise actuelle, si tout ne doit pas être perdu. Ce sereit de nouveau une erreur à-jamais déplorable que de se contenter de ce que le Roi de Prusse pent faire, pour sauver Vienne, pour empecher l' ennemi d'entrer en Bobème, ou même de forcer les François à une paix qui rétabliroit le $S t$ atus qu o a t te bellum. Cette guerre n'a pas été entreprise pour défendre la capitale ou les provinces de la Monarchie Autrichienne contre une invasion, elle n'a pas été entreprise pour empêcher cette Monarchie de perilre encure le Tyrol et Venise après tout ce qu' elle a perdu auparavint; elle n'a pas été entreprise pour maintenir le Status quo; elle a été entreprise pour le changer. Malbeur à nous tous si nous oublions ce principe fondamental! Cette guerre devoit charser les François de l'Italie; elle devoit rendre à la Suisse et à la Hollande leur vérituble indépendance; elle devoit relever l' Empire d' Allemagne et le mettre à l' abri de ces infâmes attentats dont l'Electorat d'Hannovre, les villes maritimes, dont Francfort, Carlsruhe, Munic etc. ont été successivement le théatre. Et si cette guerre ne nous conduit pas à ces ohjets, il est démontré qu' aucune autre ne le fera. Gar après cette guerre, si elle finit malheureusement, il n' $y$ a plus de ressource que dans la résignation générale, qui sera suivie de bien près par la destruction générale. Il faut donc que tout soit mis en-oeurre pour que cette guerre ne manque pas son but.

Mais elle le manquera à-coup-sûr, si on ne peut pas engiger la Prusse à y coopérer, non seulement comme auxiliaire. mais comme puissance princjpale. C'est encore bien peu de chose, si elle ne fait que détourner les François de leurs projets contre Vienne, on si elle nous sauve du malheur de signer une paix qui nous enleveroit nos derniers boulevards. La Prusse doit agir avec toutes ses forces jusqu' au dernier moment; réunie is angleterre et aux puis-ances du Nord, elle doit se charger de toute la partie septentrionale de la puissance françoise tandis que la Russie et l'Autriche opérernnt vers le Midi. Elle doit convenir avec les Cours de Londres, de Petersbourg et de Vienne, elle doit convenir préalablement des conditiony auxyurlles seules la paix générale sera signèe.

Pour l'engager dans cette route et sur-tout pour l'y maintenir, il faut trouver des aiguillons $d$ 'une force majeure. Il faut montrer à la Prusse des perspectives tellement vastes, que les François ne sorent plus capables de nous gaguer de promesses auprès d'elle. Je crois que le 
moment en est venu; je le dis en gémissant, mais on doit le déclarer, puisque telle est devenue la condition de l'existence future de tout ce qui nous est cher: Si la Prusse ne peut pas être entrainée ou consarvée à un moindre prix, il faut lui promettre même le partage de l'Allemagne avec l'Autriche. La France ne peut jamais aller au-delà, elle n' ira jamais aussi loin dans les séluctions qu' elle présentera à la Prusse. Il est vrai que le sacrifice est grand et douloureux sous beaucoup de rapports, et que celui qui a bien culcule de quai se compose lo vraie perfection d'un systême fédératif ne prononcera pis avec indifférence l'arrêt de mort de ce qui s'est encore soutenu de petits états dans la conflagration universelle de ce siècle. Mais quoiqu'il en soit, et extrémité contre extrémité, il vaut eneore mille et mille fois mieux de voir l'Europe partagée entre un certain nombre de grandes puissances que de la voir dominée et tyrannisée par une seule.

Quelque soient les mesures auxquelles vous rous portiez dans ce moment, j'ose Vous conjurer, Monsieur, de les accélérer autant que possible. Les événemens se pressent; la crise augmente; un jour de plus ou de moins peut acquérir un poils immense duns la balance. C'est moins encore que l'Angleterre entreprenne telle ou telle chose, c'est surtout qu'elle paroisse, qu'elle agisse, qu'elle exerce sur le sort de l'Europe toute l'étendue de son influence et de son autorité; abandonnés à nous seuls nous périssons sans faute; mais si le mouvement ne part pas de chez vous, il ne sera jamais ce qu'il doit être pour nous arracher à notre ruine. Le secours moral que vous nous prêterez l'emportera infiniment sur les secours pécuniaires les plus généreux que vous puissiez nous accorder.

VIII.

Gentz an Hammond ${ }^{1}$ ).

Monsieur!

Brünn le 16 Novembre 1805 .

Les circonstances dans lesquelles nous sommes sortis de Vienne ce qui est arrivé depuis que nous l' avons quittée - les nouveaux dangers qui nous ont menacés ici, et qui en même tems ont menacé l'armée Russe du général Kutusoff, qui fesoit dans ce moment-ci notre seul et dernier bouclier - la tournure plus heureuse que les affaires paroissent prendre depuis hier - l'attente dans laquelle nous sommes des heureux effets que doit nécessairement produire la révolution qui s'est opérée dans le systême politique de la cour de Prusse - tout cela Vous aura été présenté par les personnes immédiatement chargées du soin de Vous instruire. La lettre que je prends la liberté de Vous adresser aujourd'hui est consacrée à un seul objet; mais cet objet, j'ose le dire, est dans l'époque où nous nous trouvons, le plus grand et le plus décisif de tous.

L'Empereur a pris hier l' heureuse résolution de congédier le Ministre du Cabinet, Comte de Colloredo. L'imbécillité, la nullité de cet homme,

1) Die Adresse fehlt. Dass Hammond der Adressat war, ergiebt sich aus dem Postscriptum. Man vergleiche Gentz' Briefe an Starhemberg vow gleichen Datum a. a. U. S. 127. 129. 
son caractère étroit, superstitieux, sombre, ombrageux, l'horreur profonde que lui inspiroient les talens et les lumières, lorsqu'il les rencontroit quelque-part sur son chemin, enfin tout ce qu'il a contribué à la dégradation et à la ruine de la Monarihie Autrichienne, Vous sera aussi connu que la faveur inexplicable et presque miraculeuse dont il a joui depuis l'avénement de l'Empereur au trône à travers toutes les vicissitudes et toutes les catastrophes $d$ 'un des plus malheureux règnes dont l'histoire ait conservé le souvenir. On n'a pas pu encore découvrir avec certitade, si le motif de son renvoi tient à quelque sujet particulier de mécontentement et de brouillerie, ou si ce renvoi a été le résultat de quelque réflexion salutaire sur l'ensemble de nos malheurs et sur les moyens pour y mettre un terme. Dieu veuille que ce soit ce dernier motif qui l'ait dicté!

Mais quoiqu'ìl en soit l'éloignement de ce seul homme ne suffit pas pour nous relever. Un changement total, une réforme complète de ce gouvernement - ou sa chute; je vous proteste, Monsieur, devant Dieu et la vérité, dévant tout ce qu'il y a de plus sacré parmi les hommes, que cette monarchie, gouvernée et administrée comme elle l'a été jusqu' ici, mais sur-tout depuis l'année 1801, ne peut pas être sauvée, et quand même toutes les puissances de la terre et du ciel se réuniroient cent fois pour la soutenir.

Je ne veux pas, et je ne puis pas entrer aujourd'hui dans les détails d'un tableau, qui Vous feroit frémir, et dont d'ailleurs $\mathrm{j}$ ai plus d'une fois présenté les principaux traits. Il faut agir. Il n'y a pas une heure à perdre. Ce gouvernement ne se réformera pas de lui-même; il faut donc que d'autres s'en chargent pour lui. Profitons de la crise, où il se trouve maintenant; s'il n'est pas radicalement guéri cette fois-ci, il ne le sera jamais.

L'Empereur de Russie est de tous les hommes qui existent le plus propre à opérer cette révolution salutaire. Il doit à-présent avoir la mesure de ce cabinet; il a les griefs les plut légitimes contre la manière dont on a conduit les affaires; par l'infraction la plus scandaleuse des engagemens qu' on avoit pris avec lui (infraction qui a bien plus tenu à la légèreté et à l'incapacité du Ministère qu'à sa mauvaise foi) on a amené les désastres les plus affreux; on a perdu l'armée Autrichienne, on a grièvement compromis l'armée Russe, on a tout désorganisé, tout détruit. L'Empereur de Russie a donc le droit de demander un changement. Mais il s'agit de l'engager dans une démarche pareille. Il doit arriver demain; malheureusement je ne vois personne qui vouilra se charger de la besogne. Si un seul de ceux qui sont autorisés à lui faire des représentations, en pensoit comme moi, la première chose qu'il feroit, seroit de déclarer, que sass le renvoi de quatre ou cinq personnes, il ne pourroit entrer dans ancune discussion, ni assister à aucune conférence. Je dis que ce conseil ne sera pas donné à l'Empereur de Russie, puisque ceux même qui voient combien il est indispensable de le porter à une mesure pareille, ne veulent pas s'y prêter. Le Cte Rasoumoffski ${ }^{1}$ )

1) Russischer Gesandter am österreichischen Hof. Vgl. Fournier a. a. U. $\therefore 123$ u. s. w. 
est l' homme auquel les devoirs les plus sacrés préscrivent de le faire, il verroit plutôt la monarchie se briser comme un verre devant ses pieds, que d'ouvrir la bouche pour amener la seule résolution qui puisse nous arrêter au bord de l'abime. Il est triste, il est douloureux de dire ses choses-là en parlant de ceux, sur lesquels on avoit placé souvent ses espérances; mais le tems des ménagemens est passé; il faut que la vérité paroisse à-la-fin sans voile. - Dans ce terrible état des choses, je crois, Monsieur, que la seule chose à faire, seroit d'animer de Votre part l'Empereur de Russie à entreprendre ce qui est nécessaire pour sauver le continent. Dans les relations intimes, où Vous Vous trouvez avec le cabinet de Petersbourg, il est impossible que Vos conseils, renforcés par l'évidence des faits, et par la connoissance particulière que l'Empereur de Russie va acquérir de notre misère domestique ne produisent pas quelque grand. effet. Il seroit certainement à désirer qu'ils eussent pu arriver avant que l'Empereur se fut rendu dans ce pays; mais ils ne viendront jamais trop tard.

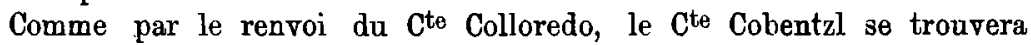
provisoirement chargé de la direction générale de toutes les affaires, je dois Vous dire, Monsieur, que cette seule circonstance est subversive de toute espérance que l'état général de la politique de l'Europe a pu nous inspirer. Le Cte Cobentzl est un excellent bomme, comme particulier; je serois le dernier à parler contre lui, puisqu'il n'a jamais cessé de me combler de bontés, de procédés de toute espèce, même d'autant de confiance qu'il pouvoit $m$ 'en accorder avec la différence fondamentale de nos principes et de notre manière de voir. Je ferois des sacrifices, pour contribuer à son bonheur. Mais enfin - la chose publique est toujours la première des considérations; et l'ignorance, l'incapacité, la fuiblesse absolue de ce Ministre est telle, que c'est une dérision, une sałyre, une épigramme que de le laisser à la tête des affuires dans un moment comme celui-ci. Il est impossible, moralement et physiquement impossible, qu'il ne précipite l'état d'une chute dans l'autre. Le Baron de Collenbach ${ }^{1}$ ), qui fait tout avec et pour lui, ajoute encore à la même incapucité un dégré d'entêtement et de malice, qui exclut tout espoir de salut. Si ces deux personnes restent en place - Vous aurez successivement compromis en pure perte, l'Empereur de Russie, le Roi de Prusse - et Vous-même, et il n'en résultera, quoique Vous fassiez, que la honte et le malheur de l'Europe.

Pour remplacer le Comte Cobentzl le choix peut se porter sur le Prince Trautmann.dorff ${ }^{2}$ ), sur le $C^{\text {te }}$ Stahremberg, sur le $C^{\text {te }}$ Stadion, sur le $C^{\text {te }}$ Metternich. Comme dans toutes les considérations humaines il y aura du pour et du contre dans le jugement qu' on portera sur chacun de ces candidats; mais chacun sera infiniment meilleur que ce qui est à-présent. Quant à Collenbach. dont le renvoi est la sine-qua-non du salut public, je vous dirai franchement que la partie éclairée du public

1) Vgl. über den Freiherrn von Collenbach, Staatsreferendar im Ministerium des Auswärtigen: Fournier a. a. O. S. 108. 109. Wertheimer.a. a. 0. Kegister.

2) Ferdinand Fürst Trautmannsdorff (1749-1827); s. Allg. Deutsche Biographie 38 , $524 \mathrm{ff}$. 
voudroit peut-etre me voir à sa place, cependant loin de pouvoir être suspect dans ce que je dis à-cause de cette circonstance personnelle, je Vous jure, Monsieur, que je regarderois comme le plus grand de tous les malheurs de devoir me charger de cette place, et que, si l'Empereur me l'offroit aujourd'hui, l'exil ou une prison m'effrayeroient moins. Je ne dis pas que je la refuserois, puisque je suis décillé à tout faire et à tont sacrifier, si je puis contribuer au bien public ${ }^{1}$ ); mais je l'éviterois de toutes les manières pussibles, et je me contenterois de recommander un homme, qui seroit avee $\mathrm{Mr}^{\mathbf{r}}$. de Collenbach à-peu-près dans la même proportion, que les quatre personnes nommées plus-haut peuvent l'être avec le Mini-tre.

Monsieur! Faites-moi la grace de conserver cette lettre. Si ce que je Vous représente ici, ne produit pas l'effet, que je désire, permettez que je la rappelle à Votre souvenir dans trois ou quatre mois! En attendant veuillez agréer l'hommage du dévouement sans bornes, et de la haute considération avec laquelle je suis sans cesse

Votre très-obéissant et très-fidèle serviteur.

Gentz.

P. S. Dans le moment que je veux fermer cette lettre j'apprends que Vous êtes arrivé à Berlin avec Lord Harrowby ${ }^{2}$ ). Cette nouvelle, permettez moi de Vous le dire, me réjouit autant que le traité d'alliance signé par la Prasse. J'y vois le présage des plus heureux changemens. Si Lord Harrowby, comme je n'en doute pas, est muni de tous les pleinspouvoirs nécessaires, qu'un des premiers usages qu'il en fera; soit donc de se mettre en correspondance avec les Ministres Russes pour réformer notre cabinet. Ce seroit plus intéressant encore, plus efficace, plus satisfaisant, si Vous pouviez venir pour quelques jours seulement voir ce qui se passe dans ce pays-ci. Je crois que $\mathrm{Mr}^{\mathrm{r}}$. Puget le désire lui-même; il doit le désirer, pour se décharger d'une partie de la terrible responsabilité qui pèse sur lui. Je Vous conjure, Monsieur, de contribuer de tout ce qui est en Votre pouvoir à l'accomplissement de ce désir. La ehose est d'autant plus essentielle, que la manière indécente dont ce cabinet tremblant renie ses liaisons avec Vous chaque fois que le cas se présente d'en faire mention, ne peut plus être passée sous silence. Je ne Vous aurois pas parlé de cet objet, si Vous étiez resté à Londres, puisque l'illée de semer les soupcons et la défiance m'auroit trop effrayé. Mais maintenant qu'il dépend de Vous de vérifier mes plaintes et de chercher les remèdes sur les lieux je ne puis pas Vous cacher cette nouvelle preuve de la plus honteuse et de la plus déplorable foiblesse. Enfin, je le répéterai, jusqu'à ce que ma plume me refusera le service: Toutes les alliances, toutes les comlinaisons politiques, tous les proiets militaires - tout est absolument nul et dénué d'effet, si la Cour de Vienne nest pas préalablement rétormée de fond-en-comble. C'est là la première de toutes les affaires et après cela je $m$ 'en remets volontiers à la sagesse des hommes

1) Vgl. die Stelle in dem Brie'e an Starhemberg a. a. O. S. 135.

2) Hammond begleitete Lord Harrowby auf seiner Mission nach Berlin. S. Näheres bei Ranke: twardenberg, namentlich V. $198 \mathrm{ff}$. Diaries and Letters of Sir George Jackson 1872 I. $380 \mathrm{ff}$. 
d'état, et aux talens des généraux, qui restent encore à l' Europe contro l'ennemi commun.

Avant tout venez voir ce qui se passe ici; car sans cola. Vous ne le croirez jamuis, et Vous ne pouvez pas le croire.

Je Vous prie de vouloir bien présenter à Lord Harrowby l'hommage de mon profond respect.

IX.

\section{(Yentz an Harrowby ${ }^{1}$ ) [?]}

\section{My Lord!}

Breslau le 27 Décembre 1805 .

Permettez que dans un des mamens les plus affreux que les amis du bien public et do l'ancien ordre des choses aient encore éprouvé, que je m' approche de Vous, pour Vous communiquer quelques réflexions bien fugitives et incobérentes sur les malheurs qui nous entourent, sur ceux, plus terribles peut-être qui nous menacent, et sur les principes et mesures à suirre dans une époque qui ressemble si peu à rien de ce que nous arons eu jusqu' ici.

$\mathrm{Si}$ cette guerre avoit eu simplement un mauvais succès, je n' en aurais pas été beaucoup effrayé, puisque je savois d'avance avec autant de certitude qu'il est possible d' en porter dans un calcul moral, qu' elle manqueroit son objet. Trois fautes capitales en avoient signalé le début. La première étoit de s'être porté à une mesure d' une aussi haute impartance. et dont la cour de Vienne devoit nécessairement être le centre et la base, sans avoir changé de fond-en-comble le llinistère qui règnoit à cette cour. Daignez vous rappeller, My Lord, ce que j' ai pris la liberté de Vous écrire i ce sujet au mois d'octobre $1804^{2}$ ), et jugez ce que j'ai dù sentir en voyant les destinées de l'Europe abandonnées aux hommes que je Vous avois caractérisés alors avec trop de vérité. La seconde faute étoit celle d'avoir fait de la Russie l'acteur principal dans une guerre, dont elle n'auroit jamais du constituer qu' un grand et respectable accessoire. Ia troisième enfin étoit $d$ 'avoir imaginé, ou que l'on pouvoit faire une guerre efficace à la France sans le concours de la Prusse, ou, ce qui étoit mille fois plus funeste encore, qu' on disposeroit de la Prusse, de gré ou de force, aussitôt qu' on en auroit sérieusement besoin. Chacune de ces trois fautes auroit suffi pour ruiner les affaires communes; réunies dans une même entreprise, il aurait fallu plus qu' un miracle pour que l' issue n' eût pas tourné contre nous.

Préparé à des malheurs inévitables, j'ai supporté ceux qui sont arrivés avec beaucoup plus de calme et de fermeté que je n'en aurois eu, si je les avois regardés, (comme beaucoup de mes contemporains ont fait) comme de ces catastrophes miraculeuses qui renversent toutes les combinaisons at

1) Die Adresse fehlt. Aber die Phrase in Gentz' Brief (s. u. S. 139), le désespoir... dont vous avez peut-être vu l'expression dans les lettres que j'écrivis à M. Jackson đ (Vgl. o. S. 114 Anm. 3) lässt darauf schliessen, dass der Adressat damals in Berlin weilte und dies in Verbindung mit der Anrede, My Lorde passt auf Lord Harrowby.

2) Der Brief fuhlt. 
confondent toutes les idées. Il y avoit, sans doute, dans l'horrible défaite de l'armée de Mack, des détails tellement cruels et tellement ignominieux qu'ils passoient de loin l'attente la plus mélancolique; mais le résultat général étoit jusques-là analogue à ce que j'avois préru; et le petit nombre de personnes qui ont connu Vienne comme moi ont partagé avec moi l'espèce de résignation que nous trouvions dans l'accord mêne de ces tristes événemens avec les calculs par lesquels nous les avions anticipés.

La perte de Vienne fut une suite naturelle et irréparable des premiers désastres. Il n'y avoit qu' un seul homme qui eut pu la prévenir; e'étoit l'Archiduc Charles; mais je le connoissois trop pour ranger seulement dans l'ordre des choses possibles les efforts qu'il auroit fallu qu'il fit pour détourner ce coup. Après tout je Vous assure, My Lord, que loin de regarder l'état des choses comme désespéré dans le moment que nous quittions la capitale, je persistai à croire et à dire, que malgré l'énormité des pertes individuelles et de l'embarras local, l'ensemble des rapports politiques étoit plus rassurant qu'il ne l'avoit été dans aucune époque quelconque depuis la révolution de France. Le Ministère Auirichien, quoique plus $q u^{\prime}$ incapable, quoique nul, quoique directement responsable de tous les revers que nous avions essuyés alors, avoit été cependant retenu dans le bon chemin, soit par la honte, soit par la crainte ile se brouiller avec toutes les grandes puissances qui parojssoient alors plus que jamais marcher dans la même direction. La proclamation de Brünn, après les conditions que les François avoient voulu attacher à l'armistice, étoit certainement une pièce remarquable pour ceux qui connoissoient les personnes des mains desquelles elle étoit sortie. Je me fais gloire d'y avoir contribué; et malgré les sinistres présages qui assiégoient déjà mon âme, ce séjour de Brünn $m$ 'avoit vraimen trendu la vie, tant à-cause des excellentes nouvelles qui nous arrivoient alors de Berlin, qu'à cause des bonnes dispositions que je trouvois encore dans le Cte. Cobentzl; ayant l' occasion de lui parler chaque soir, et presque tête-à-tête chez la Princesse Dolgorouky ${ }^{\mathfrak{l}}$ ), je me félicitai sans cesse de pouvoir le fortifier dans le bien, par les éloges que je ne cessois de lui faire sur sa fermeté, et par les tableaux lugubres que je lui présentai dans les suites d'un systême opposé.

Cependant chaque jour $m$ 'éclairoit davantage sur l'impossibilité de remettre l'Autriche dans une activité salutaire aux intérêts communs, si on ne trouvoit pas le moyen de renforcer et de reconstituer le Ministère. Je me croyois presque sûr, que l'arrivée de l'Empereur de Russie d̀ 0llmütz ameneroit cet événement, condition préalable de tout salut et de tout rétablissement quelconque. L'Empereur de Russie s'y refusa. Il vit toute l'étendue du mal; mais au-lieu d'y porter le remède, il se livra à un mécontentement stérile, et à un désir immodéré, et je ne crains pas d'ajouter, déplacé, de sauver sa gloire en attaquant les François à tout hazard et événement. Cette conduite, résultat $d$ ' une erreur que l'on doit honorer encore, tout en se voyant obligé de la déplorer, a finalement perdu l'Europe. Bi l'Empereur de Russie avoit employé tous ses moyens et tous son crédit,

1) Fürst Dolgorucky Generaladjutant des Zaren. Vgl. Wertheimer: Register. Gentz: Tagebücher I. 42 und seinen Brief an J. v. Müller vom 14. Dec. 1805 bei Schlesier IV. 157. 
pour engager, pour for cer l' Empereur d' Allemagne à prendre sur-le-champ toutes les mesures qui lui restoient encore pour réunir et concentrer ses forces, à chasser les hommes foibles qui ruinoient ses affaires; à s' entourer de tout ce qu'il $y$ avoit dans son pays de vigueur et de talens, si en opérant cette révolution salutaire, il avoit soigneusement évité tout engagement: décisif avec les François, avant l'arrivée de tous ses renforts, et avant les premiers mouvemens de l'armée Prussienne, une perspective brillante s'ouvroit de toutes parts. La simple marche d'un corps de Prussiens de $80^{\mathrm{m}}$ hommes vers Ratisbonne mettuit les François dans l'évidente nécessité de quitter la position de Vienne; dans ce moment plus de $120^{\mathrm{m}}$ Russes s'élevoient pour les suivre, l' armée de l'Archiduc Charles portée par les corps-de-réserve, par des mesures efficaces, et par des hommes dignes d'agir dans ces circonstances à plus de $130^{\mathrm{m}}$ hommes donnoit la main aux Prussiens d'un côté et aux Russes de l'autre; et l'espoir de nous voir vengés à-la-fin de tant d'affronts et de désastres $n$ 'étoit plus un espoir chimérique.

L'Empereur de Russie, en négligeant d'un côté la grande affaire de la restauration du cabinet de Vienne et abandonnant d' une certaine manière l'Autriche à son sort, en confiant de l'autre côté les plus grands intérêts de l'Europe au sort d' un seul combat, prépara l'effroyable journée du 2 Déceinbre, la plus funeste de toute l' histoire moderne; après celle du 14 Juillet 1789! Le désespoir dont je fus saisi à la nouvelle de cette bataille, et dont vous avez peut-être vu l'expression dans les lettres que $j^{\prime}$ écrivis à $M^{r}$. Jackson ${ }^{1}$ ), n' étoit pas produit par la grandeur de la perte que nous $\mathrm{y}$ avions faite; des batailles plus sanglantes ont été livrées sans entrainer la centième partie du malheur que celle-ci devoit causer. Mon découragement - c'est la première fois que j' ai articulé ce mot depuis que je sers sous les drapeaux de cette cause sacrée et malheureuse provenoit uniquement de ce qu' avec la connoissance trop exacte que j' avois de l' ensemble de notre situation, il m' étoit impossible re ne pas prévoir que cette bataille tueroit la coalition. Si je n'avois pas eu cette crainte, hélas, trop-tôt réalisée, je Vous le jure, My Lord, la cessation même de la guerre ne m' auroit pas ahsolument déconcerté. Je crois qu'il auroit été à-peu-près impossible de la continuer après cet événement. Car la Russie, quoiqu' on vous dise, étoit hors de combat pour quatre ou six mois; déterminer l'Autriche à agir vigoureusement étoit devenue (après la bataille d'Austerlitz) une entreprise au delà des forces humaines; et engager la Prusse à se lancer seule dans l'arène, quand même la chose auroit été possible, étoit peut-être un projet, dunt on se seroit amèrement repenti. Mais voici quel étoit à-peu-près mon raisonnement. Si la coalition ne se dissout pas, le pis qui puisse arriver est une paix avec la France qui sans doute, dans les circonstances du moment, ne sauroit être qu' infiniment désavantugeuse. Analysons toutefois de près la profondeur de cet abîme. La Russie n' y perdra rien; la Prusse n'y perdra rien; il est même plus que vraisemblable, que les François ne pourront plus reprendre leurs positions dans le Nord de l'Allemagne. Supposons que l'Autriche soit forcée à sacri-

1) S. o. S. 114 Anm. 3. 
fier une ou deux de ses provinces. En sera-t-elle beauconp plus malheureuse qu' elle ne l'étoit après la paix de Lunéville? Certainement pas. Et l'Europe se trouvera-t-elle par cette perte dans une position beuucoup plus désespérée, que celle dans laquelle la paix de Lunéville, et les quatre années qui ont suivi cette paix. l'avoient jetée? Certainement pas. $\mathrm{Ni}$ l'Autriche, ni l'Europe ne pouvoient rester dans l'état où elles se trouvoient, avant que la guerre actuelle eut commencé. Voilà le point-de-vue essentiel! Or, la guerre actuelle ayant manqué son objet, la grande, ou plutôt la seule question, digne d'occuper les hommes d'état étoit toujours elle-ei. Quels sont les mojens de fonder une nouvelle guerre, une guerre, plus efficace et plus heureuse, pour arriver au but que celle-ci n' a pas atteint? Que l'Autriche retournat au Status quo établi par la paix de Lunéville, ou qu"elle perdit encore quelques provinces de plus, ces deux résultats funestes n'étoient séparés que par une nuance peu considérable; elle, et l'Burope, ne pouvoient subsister ni avec l'un ni avec l'autre de ces résultats. Donc tout, absolument tout étoit attachè à la conservation intacte de la coalition, comme du seul et unique moyen pour rétablir plutôt ou plus tard l'équilibre et l'independance de l'Europe. Si la paix que l'on alloit faire, et que, selon moi, on étoit forcé de faire (après toutes les fautes par lesquelles on avoit rendu le succès impossible pour le moment) si cette paix étoit nne paix générale, seulement dans l'acceptation la plus vague du mot, et si le concert, heureusement et presque miraculeu-ement établi entre l' Angleterre et les trois puissances continentales survivoit a cette paix, je soutiens, et je me fais fort de le prouver à tous ceux qui sont capables de réfléchir, que même en perdant l'état de Venise, les possessions de Souabe, et jusqu' ì une partie du Tyrol, nous étions moins eloignés d'un changement décisif dans les affiires générales de l'Europe que nous l'avions été dans toute la période qui s'est écoulée depuis la paix de Basle jusqu'au mois de Septembre 1805. 'Tout ce que nous aurions signé maintenant, auroit été une trève, pendant laquelle nous aurions organisé par des efforts communs les moyens de sortir à-la-fin $d^{2}$ une manière complète et satisfaisante $d^{\prime}$ un état des choses incompatible avec les premières conditions d' une existence politique honorable et indépendante, incompatible avec la conservation d' une société Européenne libre et eivilisée.

Le coup mortel dont nous ne nous relèrerons plus n' étoit donc point la bataille d'Austerlitz en elle-même, ce n'étoit même point la nécessité d'une piix subite et désastreuse; c'étoit la destruction de tous les liens qui s'étoient formés entre les puissances, le retour à cette affreuse anarchie politique dans laquelle les François avoient déjà puisé jusqu' ici tous leurs effroyables succès, et qui désormais leur fournira les moyens de nous subjuguer pour toujour. Lorsque j'ai appris l' entrevue de l' Empereur avee Bonaparte - l' armistice scandaleux qui en est résulté - le départ de l'Empereur de Russie - lorsque j' ai vu l' acharnement et la haine qui animoit réciproquement les Autrichiens et les Russes - lorsque je n' ai plus pu me dissimuler, que c'étoit en vain de conpter encore sur l'intervention des Prussiens - lorsque j'ai deviné ${ }^{1}$ ) et puis de plus-en-plus connu avec

1) Ms. j'en devins. 
certitude la tournure que prenoient les négociations de Mr. de Haugwitz à Vienne - lorsque j' ai va reparoitre les plaintes forcenées et le mécontentement stupide contre l' Angleterre - lorsque j' ai vu s' anéantir tous les germes d'une intelligence future -

Tunc vero omne mihi visum est considere in ignes

Ilion, atque ab imo verti Neptunia Troja!

Je suis infiniment éloigné de croire, My Lord, que les limites de ma perspicacité soient celles de tuute perspicacité humaine. Mais je vous avoue en même tems, que je suis convaincu, qu' il n' existe pas dans ce moment-ci un homme qui puis:e concevoir ce que l'Europe sera dans six mois. In est clair, que toutes les anciennes ressources, que toutes les anciennes combinaisons ont finalement disparu - et que, si les débris de l'ancien ordre des choses peuvent encore être conservés, ce sera par des moyens. dont à-présent personne ne peut se former la moindre idée. Nous sommes placés à l' entrée d' une carrière, dont nous ne connoissons pas même les pointis les plus prochains, et dont le terme est couvert des ténèbres les plus épaisses. Mais suit que nous nous trouvions arrivés à l'époque de l'asservissement universel et de la destruction universelle, soit que le désespoir crée des armes, qui jusqu' ici nous étuient inconnues 1) d' une manière ou de l'artre - un nouveiu monde va s'ouvir.

Dans cette affreuse incertitude, à-la-veille de cette conflagration générale, il n'y a plus qu' un seul fragment de l'ancien édifice social, sur lequel l'oeil se purte avec une satisfaction toujours renouvellée et un intérêt toujours soutenu. Le continent est perdu; et quoiqu'il en coute à ceax qui au miliru du bouleversement et des ruines, ont conservé les sentimens qui fesoient autrefois l'ornement et la gloire des nations, quoiqu'il leur en coute de le dire: le continent a mérité de périr, et il ne vaut plus la peine de s'uciuper des moyens de le sauver malgré lui, et de se consumer en vains efforts, pour une cause ingrate, désespérée, et trahie par ceux mêmes qui étoient. les plus directement intéressés à la soutenir. Mais l'Angleterre! Doit-elle être entrainee dans cette chute mortelle? Doit-elle périr avec nous? L'indifférence du désespoir, l' assoupissement le plus profond, la stupeur neême de la mort ne sauroient nous retenir à cette question; le tombeau, où le continent est enseveli, doit se rouvrir pour renvoyer à la lumière tout ce qu'il renferme encore de forces et de moyens contre une catustrophe, dont le genle humain ne se relèvero:t pas dans des milliers de siècles. My Lord! Je vous crois toucher à un moment, qui vous obligera à faire une revue générale de l'ensemble de Votre situation. L'Angleterre peut-elle se passer du continent? Si elle ne le peut pas, que restr-t-il à faire pour le conserver? Je crois que ces questions fondamentyles doivent être approfonilies et décidées avant que vous aduptez votre systême politique anx nouvea'x problêmes que vous aurez à résoudre. J'ai long-temprs teliu à l'opinion contraire: mais je sais, que, si j'étois admis anjourd'hui à vos conseils j'inclinerois fortement vers le parti d'abandonner le continent. Sous le rapport politique et militaire il n' existe au-fond qu'un seul danger pour vous; ce danger est certainement moins terrible qu' on ne l'avoit supposé arant d'être fumiliarisé avec lui, et une nation telle que la vôtre saura se délendre. Mais que ce danger soit granid

J) Ms. inconnus. 
ou petit, prochain ou éloigné, il est toujours incontestable, que le continent ne peut se détourner de vous que par un seul moyen: en arrachant la Hollande, les Pays-bas, et l'Espagne au bras-de-fer du gouvernement Fran६̧ois; et cette opération ne se feroit pas dans un demi-siècle, quand même il resteroit encore un état indépendant en Europe. Sous le rapport commercial vous êtes invulnérable. $\mathrm{Si}$ les François occupoient dès demain tous les ports et toutes les rivières du continent, votre commerce (sans compter qu' il a d' autres bases et d' autres débouchés que ceux de l' Europe) n'en seroit pourtant pas exclu. Le même désir immodéré des jouistances, le même égoisme, les mêmes dispositions de l'ame, qui vous ont aliéné le continent comme Allié politique, Vous le garantissent comme Allié commercial; les êtres qui le composent ne sont plus capables d'apprécier votre grandeur nationale, et de sentir le besoin de votre amitié; mais ils ne peuvent pas se passer de vos marchandises; et ils s'exposeront à tout plutôt que de s'en priver. Tant que votre marine sera ce qu' elle est, vous ferez le commerce du monde, que ce monde vous aime ou vous déteste. Je crois donc, qu' en toute vigueur vous pourriez exister sans aucune alliance sur le continent. Mais les conditions, sous lesquelles ce parti peut seul être embrassé sont sévères et imposantes. Si vous l'adoptez, il ne faut jamais faire de paix avec la France; il ne faut jamais souffir que la marine Françoise se relève; chaque semaine de paix, chaque batiment que vous lui permettez de construire sera - dans cette position forcée — un acheminement vers votre ruine. Je suis persuadé, que vous trouverez les moyens d'organiser cette guerre perpetuelle d' une manière compatible avec une grande économie, que lorsque vous aurez bien étudié cette nouvelle inéthode d'exister, elle ne vous coutera pas, année commune, le tiers de ce que vous dépensez à-présent. Mais une des premières résolutions à prendre sera alors de déclarer illicite et contrebande tout commerce quelconque que les nations neutres, ou prétendues amies voudroient faire avec la France et ses possessions. Il ne faut s'arrêter $\dot{a}$ aucune vaine considération. Que vous font les cris d' une poignée de Danois, de Prussiens, ou même d'Américains, quand il s'agit de sauver l'Angleterre? Et quels ménagemens les nations continentales ont-elles encore à vous demander après l'indigne conduite que toutes - sans exception - cabinets comme individus - ont tenue contre vous depuis dix ans? Arec cette mesure contre les neutres, cent-mille hommes de bonnes troupes dans votre pays, l'esprit qui vous a animé jusqu'ici, et des héros qui gagnent des batuilles de Trafalgar, Bonaparte tyranniseroit l'Europe pendant trente ans, et il ne vous atteindroit jamais.

$\mathrm{Si}$ ce systême vous paroit trop téméraire, il ne vous reste qu' à jeter encore une fois les yeux sur le continent. Mais dans ce cas-là le premier de vos soins sera d'en créer un autre que celui qui vous a ruinés et trahis jusqu' à present. Je ne puis pas entrer ici dans les moyens d' exécuter une révolution pareille; mais an risque même de Vous puroitre visionnaire, my Lord, je soutiens pour le moment que ces moyens existent, sauf à les développer, lorsqu' on jugera convenable de me les demander. Mais toutes les routes hattues doivent être abandonnées pour cet effet; et s'il faut beaucoup de courage pour vous séparer entierement du continent, il faudra beaucoup de sacrifices pour le changer. 
Dans l'un et l'autre cas, je Vous supplie, My Lord, non-seulement de ne pas me repousser de la communion honorable dans laquelle je me suis trouvé avec Vous jusqu' à présent, mais de resserrer mème les liens qui m' unissent à votre cause. Comme le mérite d'un général ne peut pas toujours être estimé par les résultats de ses campagnes, de même il seroit injuste de me juger sur les succès que $j$ ' ai obtenus. J' en ai peu à présenter; mais des témoins irrécusables attesteront un jour ce que j' ai fait pour les intérêts de la cause et encore tout particulièrement pour ceux de l'Angleterre pendant les quatre années que j'ai passées à Vienne. "Si Pergama dextra - defendi poterint etiam hac defensa fuissent" Je dois même le dire - mille fois j' ai eru toucher à la victoire, et elle aurait été remportée, _- _ si j' avois pu être soutenu! Maintenant, qu'il $s$ 'agit de poser les fondemens d' une nouvelle existence politique, quelque soit le parti, que vous prendrez, daignez m' y admettre pour quelque chose. $\mathrm{Si}$ vous vous déterminez à chercher quelque nouvelle liaison continentale, veuille $z$ m'employer par-tout où vous aurez hesoin d'une activité zélée et infatigable; mettez-moi au poste le plus périlleux; ce sera ma gloire et mon bonheur, de vous servir ou de sucromber. Si au-contraire vous vous renfermez dans votre pays, la seule, la dernière grâce que je vous demanderai sera celle de m'y renfermer aussi. $\mathrm{Si}$ je savois écrire en Anglois comme j'écris en Allemand et en François je ferois valoir cette fuveur même par des efforts continuels pour diriger et soutenir l' esprit public, à-présent je la regarderois comme une retraite honorable; car du-moment que vous faites divorce avec le continent, je ne puis pas balancer sur le parti qui me reste $\dot{a}$ embrasser.

Avant-tout, My Lord, je Vous demande avec les plus vives instances quelques lignes seulement de réponse à cette lettre. Veuillez les adresser à Dresde où je me rendrai dans quelques jours. Mon zèle ne se rallentira jamais, mon courage est à toute épreure; cependant je sens le besoin d'être raffraichi de tems-en-tems par quelque parole d'approbation et de confiance pour mieux supporter les peines que j'éprouve à chaque pas de ma triste carrière. Agréez, en attendant l' hommage du plus profond ot dn plus respectueux dévonement avec lequel j'ai l'honneur d'être,

My Lord!

Votre très-humble, très-obéissant et très-fidèle serviteur

Gentz.

$\mathbf{X}$.

Gentz an Hammond [?] 1).

Prague le 14 fevrier 1808.

Monsieur!

Le départ de $\mathrm{M}^{\mathrm{r}}$. Adair ${ }^{2}$ ) va rompre les derniers points-de-contact, que j'avois pu conserver avec l'Angleterre. Désormais les ténèbres de la

1) Die Adresse fehlt. Ich wage nur die Vermutung, dass Hammond der Adressat war.

2) Kobert Adair (1763-1855) damals englischer Gesandter in Wien, das er nach dem Bruch Oesterreichs mit England am 1. März 1808 verlassen musste s. Wertheimer: Geschichte Oesterreichs und Ungarns n. s. w. II. 2:1. Vgl. 
plus cruelle solitude vont couvrir le continent à mes yeux. Permettez, Monsieur, que dans ce lugubre moment je Vous adresse mes derniers hommages.

Quand j' ai vu à-la-suite deś conférences de Tilsit, la Russie, frappée d' un areuglement mortel, conjurer contre son premier Allié et l'Europe courbée sous le joug, en obéissant aux ordres de son tyran, consolider sa ruine par les efforts qu' elle lait pour amener la vôtre - j'ai eu un instant des inquiétudes. Il n' en existe plus aujourd' hui. Cette réunion de force et de sagesse, qui a caractérisé chacune de vos démarches, ce calme, cette dignité parfaite, qui règnent dans toutes vos pruductions, cette vigueur, ceite nolle fierté, qui se sont déployées dans toutes vos mesures, cette contenance simple et sublime, adoptée au milieu des orages - m' ont rendu le courage et l' espérance. L'Angletterre ne périra point; elle bravera tous les dangers; elle triomphera de toutes les conspirations; elle confondera tous ses ennemis ${ }^{1}$ ).

J'uborde donc, sans crainte ef sans murmures, la perspective qui s' ouvre devant moi, quelque douloureuse, quelqu' eff'ayante qu' elle puisse être. Etranger, dans mon propre pays, par les principes dans lesquels je veux vivre et mourir, privé de la seule consolation qui me restoit après tant de catastrophes, de celle de quelque communication avec l'Angleterre, condımné pour un tems illimité à apprendre des fragmens de votre bistoire par les canaux les plus impurs et les plus orlieux - je m' en vais imiter en petit l' exemple, que vous m' avez donné en grand. Je ne désespérerai point da salut public; réduit à mes ressources solitaires, ne découvrant plus autour de moi que des ennewis achurnés et pertides, ou de laches et inutiles amis, je ne cesserai cependant de combattre pour votre cause avec les armes, que Dieu m' a confiées, et que l' enfer ne m' arrachera pas, avant de m'avoir arraché la vie.

Monsieur! C'est un mot simple et commun; mais prononcé dans ce terrible moment, e'est un mot solemnel et sacré: Veuillez ne pas m'oublier! Si Vous trouvez un moyen quelcolique pour me taire parvenir le moindre signal de bienveillunce, la moindre murque de souvenir, daignez croire, que ce sera une vision céleste, qui éclaireru et embellira pour long-tems l' enceinte de ma triste prison.

Agıéez, Monsieur, l'assurance de la plus sincère admiration, du dévouement le plus inviolable, et du très-profond respect, avec lesquels je suis,

\section{Monsieur!}

Votre très-humble, très-ohéissant et trés-fidèle serviteur Gentz.

Sir Robert Adair: Historical memoir of a mission to the court of Vienna in 1806 \%. s. w. 1844 .

1) Vgl. Gentz an Ludwig von Ompteda 11. Feb. 3808 , Halb hat Fagland schun gegiegte u. s. w. Politischer Nachlass L. v. Ompteda L. $3+9$. 
XI:

Gentz an Canning ${ }^{1}$ ).

P. le 3. Mai 1808 .

Une vaste conspiration entre la plus terrible tyrannie, qui ait jamais écrasé l'Europe, et la lâcheté la plus révoltante dont aucune génération se soit rendue coupable, travaille depuis un an à dérober au continent tout ce que pourrait l'éclairer sur ses intérêts, relever son courage et adoucir le sentiment de sa misère, de sa honte et de sa mort.

Mais Vous, Monsieur, Vous avez su déjouer cette conspiration. Dès la première époque de $\nabla$. Ministère, Vous Vous êtes élevé, Vous Vous êtes fixé à une hauteur, où se brise nécessairement ce que la tyrannie la plus raffinée pouvait imaginer d'entraves et de stratagèmes. On peut nous ravir les détails du spectacle imposant, que présente aujourd' hui l'Angleterre; on peut enchainer les communications; on peut supprimer, tronquer ou falsifier chaque mot qui se dit, chaque ligne, qui s'écrit chez Vous. Mais on ne peut plus cacher, ce que Vous avez fait, ni ce que vous faites. Ce ne sont après-tout que les accessoires qu' on réussit à nous enlever; les grands résultats nous restent; ils bravent et braveront toujours les inutiles efforts de nos cruels oppresseurs.

Ce n' est pas, Monsieur, pour articuler quelquels vains et stériles complimens; ce n'est pas même - quelqu' excusable que paroitrait un motif pareil - pour faire sentir à un Ministre, si digne de la reconnaissance universelle, qu' au milieu de notre dégradation il existe encore des âmes capables d'apprécier le mérite et la grandeur, c' est avec un but beaucoup plus grave et beaucoup plus essentiel que j'ose Vous adresser ces lignes. Dans la triste séparation, où on nous a réduits, il me paraît important et nécessaire que quelqu' un qui par une longue expérience et des relations aussi intéressantes qu'étendues, se croit en état de reconnaitre et d'interpréter l'opinion publique du continent, lui serve d' organe auprès de Vous. Il me parait important et nécessaire, non seulement pour Votre propre satisfaction, mais aussi pour les plus grands intérêts de notre temps que Vous n'ignoriez. pas, sous quel point-de-vue la partie saine et estimable du public envisage aujourd' hui Votre situation et Vos démarches.

Je, ne veux pas remonter à l'époque où Vous et Vos respectables collègues Vous chargiez de l'administration des affaires. Par des raisons que je ne puis pas développér ici, les voix étaient alors très partagées (et je ne parle que des personnes bien pensantes) sur les effets probables du changement qui s'était opéré. Quant à moi je ne pouvais pas même me livrer à un doute. Mes principes et les connaissances que $j^{\prime}$ avais acquises sur les personnes et les choses en Angleterre suffisaient pour régler mon jugement, i]. a été invariable; je $\mathbf{m}^{\prime}$ en félicite, sans $m$ ' en pouvoir faire un mérite.

1) Der Brief ohne Unterschrift von der Hand eines Schreibers, mit der ohne Zweifel in London zugefügten Bemerkung, through Mr. Coutts'(s. o. S. 109 Anm. 5) hat keine Adresse, aber der Inhalt ergiebt, dass Canning der Adressat war. Aus Vorsicht wurde selbst der Ort der Absendung "Prage nur durch, P.\& angedeutet. 
L'événement de Copenhague 1) avait répandu quelques inquiétudes parmi les plus sincères de vos amis et $j$ 'aroue que je les partageais à un certain point ${ }^{2}$ ). Sans être un instant en peine pour justifier la base de cette expédition, je craignais que l'industrie infernale de nos persécuteurs ne trouvât les moyens de la calomnier, de la dénaturer si complètement aux yeux du public, qu'il en résulterait de nouvelles préventions, de nouvelles haines contre le gouvernement Anglais. Si cette crainte s' est trouvée fondée pendant quelques momens, il est tout aussi certain que l'effet final n' a nullement répondu à l'attente de l'ennemi.

Lorsqu' on a vu paraitre la déclaration de guerre de la Russie, une autre crainte s' est emparée de ceux qui font des voeux pour la conservation et les succès de l'Angleterre. Ils se sont demandés, si le Ministère Britannique aurait assez de confiance dans ses forces, dans la magnanimité de sa nation pour affronter ce nouvel orage, pour se mettre en état de guerre avec toute l'Europe, pour exposer son commerce à des privations douloureuses etc. etc. Quant à cette crainte, elle ne m'a jamais gagné; j' ai anticipé, j'ai prédit l'événement; mais avant que l'on en fut absolument sûr, un intervalle $d$ 'incertitude cruelle a, pour ainsi dire, suspendu la respiration de tout ce qui Vous est sincèrement attaché.

Votre sublime contredéclaration a mis fin à toutes les incertitudes. Du moment qu' elle a paru, l' opinion a pris son assiette ${ }^{3}$ ).

Si Vous n'aviez opposé à cetle crise sans exemple que la même persévérance inébranblable, par laquelle Vous avez déjà fait à l'ennemi commun plus de mal réel que n' ont pu lui faire les opérations réunies de toutes les puissances continentales, Vous auriez été à juste titre l'objet de l'admiration et de l'enthousiasme de tout homme qui sait distinguer la véritable grandeur. Le calme et la dignité qui règnent dans Votre réponse à la Russie et dans le ${ }^{4}$ ) discours vraiment majestestueux par lequel le Roi a ouvert la session actuelle du Parlement ne pouvaient échapper à personne. Vos ennemis et Vos détracteurs en ont pâli; jugez donc quels devaient être les sentimens de ceux qui Vous étaient restés fidèles ${ }^{5}$ ).

Mais Vous ne Vous êtes pas borné à une simple résistance défensive, quelque belle, quelque superbe qu' elle eût toujours été dans un moment aussi singulièrement menaçant. L'énergie extraordinaire que Vous avez déployée Vous a porté tout-à-coup à une élévation qu' aucun de Vos prédécesseurs n'avait pu atteindre. Les mesures aussi sages, aussi justes et légitimes que décisives, par lesquelles Vous avèz répondu aux décrets qui Vous fermaient le continent - l'imposante égalité de conduite, que Vous avez observée vis-à-vis du Gouvernement Américain ${ }^{6}$ ) — la vigueur

1) Die Beschiessung Kopenhagens und die Abführung der dänischen Flotte im September 1807.

2) Vgl. Gentr: Bemerkungen in seinem Brief an Ompteda 26. August 1807. L. von $0 \mathrm{mpted}$ a Politischer Nachlass I. 317.

8) Gentz hatte Bemerkungen über die russische Deklaration und die englische Gegendeklaration verfasst und sandte sie an Canning s. Gentz: Tagebücher I. 53. L. von $0 \mathrm{mpteda}$ a. a. O. S. 337. 347 .

4) Ms. ,lese.

5) Vgl. Gentz an Ompteda 19. Februar 1808 a. a. O. S. 351.

b) Vgl. z. B. Brosch: Geschichte von England IX. 321, 404 über die englischen Geheimxatsbefehle vom 11. Nov. 1807 und die dadurch erzeugte Spannung mit den Voreinigten Staaten. 
que Vous avez su finalement inspirer à la cour de Lisbonne et ce grand et magnifique dénouement de la tragédie qu' on préparait an Portugal 1) - l'usage que Vous avez fait de la noble constance du Roi de Suède, les secours que Vous lui avez fournis, ceux, qu' il est à la veille de recevoir et les puissantes opérations qui se préparent ou s'éxécutent aujourd' hui dans la Baltique, dans la Méditerranée et j' espère aussi dans l'Amérique méridionale - enfin tout ce que nous avons vu depuis six mois et tout ce que nous sommes autorisés à nous promettre après un début pareil, devait relever les âmes les plus timides et pénétrer des plus belles espérances ceux qui avaient conservé l' habitude de regarder l' Angleterre comme la dernière ressource du salut commun.

La mémoire de Mr. Pitt est justement et sera éternellement révérée. Mais déjà - ce n' est pas là une opinion particulière, il serait arrogant de Vous l'offrir - un fait, un simple fait, que je me crois en devoir de Vous transmettre: déjà les meilleurs juges parmi les contemporains sont persuadés, que sous les rapports principaux et essentiels Vous avez surpassé la gloire de Mr. Pitt.

Après cela, Monsieur, que pourrais-je ajouter? - Entrer dans des détails de l' état du continent serait peu convenable dans une lettre qu'au défaut de tout autre moyen moins dangereux je dois livrer à tous les hazards. Mais daignez croire que quelque-chose que l' on fasse pour perpétuer cette triste séparation, il existe et il existera toujours sur le continent des hommes bien déterminés à tout entreprendre pour servir Votre cause, qui est celle de la justice, de la liberté et de la prospérité générale; des hommes qui occupés jour et nuit d' une seule et même pensée, s'en remetient à des tems plus beureux pour faire paraitre le résultat de leurs travaux, qui savent tirer profit des circonstances les plus difficiles et en apparance les plus défavorables et qui ne connaissent d'autre objet ni d' autre gloire au monde que de préparer en secret la réaction tôt ou tard inévitable qui doit nous délivrer de tant d' opprobre et de tant de malheurs.

Je n'ai pas besoin de signer cette lettre dont Vous devinerez bien l'auteur. Je n' ai pas non plus besoin de Vous parler de ses sentiments personnels, de son profond respect, de son dévouement inviolable.

\section{P. S.}

V. E. recevra par une autre voie une lettre concernant un objet particulier, pour lequel celui qui l'écrit se réfère à celle qu'il a adressé à Mr. Hammond au mois d'aout $1807^{2}$ ). Une partie de ce que celle-ci contenait, a été réalisée au gré de ses voeux, le reste, étant dans la même catégorie et tenant en outre $\dot{a}$ des objets pour lesquels il peut compter sur Fotre intérêt illimité, il a fait de nouvelles tentatives pour l'obtenir. Sauf à prouver un jour co mbien il était justifié en Vous adressant cette demande, il conjure V. E. d'y faire droit et de donner dès-à-présent les ordres nécessaires pour cet effet.

1) Die Abreise des Prinzregenten nach Brasilien.

2) Dieser Brief fehlt. Er wird sich auf Geldangelegenheiten bezogen baben. Vgl. Gentz: Tagebücher I. 53. 1808 . . Im Mai wurde mir.. ein bedeutender Kredit in England eröffnet, der mich anf einmal allen drückenden Sorgen entzog*. 


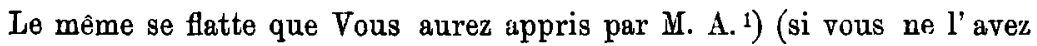
pas trouvé dans une de ses lettres précédentes) le projet qu'il a formé pour l'avenir. Ce projet est inséparablement lié à l'article précédent; mais il exige de plus Votre approbation. Ne serait-il pas possible, qu' on lui fit parvenir quelques lignes de réponse, en les adressant, par exemple, à Stockholm?

Le même prie V. E. de le rappeler au gracieux souvenir de M. le Duc de Portland ${ }^{2}$ ) et de Mr. le Marquis de Wellesley ${ }^{3}$ ), qui l' en a honoré dans le tems même qu' il courut sa glorieuse carrière dans l' Inde.

\section{XII. \\ Gentz an Canning.}

Prague le 19 Mai 1808.

Des lettres que j' ai fait partir par différentes voies et dont au moins l' une ou l' autre parviendra à Votre Excellence Lui exposeront, avec d'antres objets bien plus intéressants que ceux qui me regardent, la raison par laquelle $\mathrm{j}^{\prime}$ ai dû $\mathrm{m}$ ' adresser à ceux qui sont chargés de cette lettre, pour une affaire qui ne peut pas être réalisée sans les ordres de Votre Excellence. Je ne puis reprendre ici aucun des détails. Je me contente de prier avec les plus vives instances, qu' on daigne ne pas refuser le consentement nécessaire, et m' accorder assez de confiance pour croire, que $j$ 'en justifieroi pleinement et amplement l'utilité et la nécessité ${ }^{4}$ ). Voilà tout ce que je puis me permettre de dire ici, mais Votre Excellence suppléera au-reste; et pour que le Ciel favorise l'expédition de la présente, je sais avee certitude, que mes voeux sont remplis.

Nota manus.

XIII.

Gentz an Canning ${ }^{5}$ ).

Monsieur!

Prague ce 15 Juin 1808.

Je trouve enfin une occasion, qui me paroit suffisammment sûre, pour que je lui livre une petite partie au moins de ce que j'aurois à dire à Votre Excellence si ma plume étoit aussi libre, que mon coeur est pressé par le besoin de s'ouvrir avec Elle.

$\mathrm{Je}$ ne sais pas, si une seule, et laquelle des nombreuses tentatives, que j'ai faites depuis six mois, pour me faire entendre en Angleterre, a réussi. Je ne sais pas, si les papiers, que $\mathrm{j}$ ' avois remis à $\mathrm{M}^{\mathrm{r}}$. $\Lambda$ dair lors

1) Adair, s. o. S. 143, Ann. 2. Worauf sich Gentz projet bezieht, wird durch eine Stelle des Briefes vom 15. Juni 1808 (s. u. S. 153) aufgeklärt. Er plante eine neue Reise nach England.

2) Bentinck William Henry Cavendish, dritter Herzog von Portland (1738 -1809) Staatssekretär des Innern 1794-1801, Premierminister 1807-1809. 8. Dict. of Nat. Biography IV. 302 . Indien.

3) Wellingtons Bruder (1760-1842) 1797-1805 General-Gouverneur von

4) Vgl. o. S. 147, Anm. 2.

5) Die Adresse fehit, ergiebt sich aber aus dem lnhalt. 
de son départ de Vienne ${ }^{1}$ ), sont arrivés; car j' ai appris avec la plus grande surprise, qu' au lieu d'aller en droiture à Londres, il a changé de route à Palerme, et se trouve peut-être aujourd' hui à une grande distance de l'Angleterre. Je me flatte cependant, qu'il aura trouvé le moyen d'envoyer à Londres tout ce qui n'appartenoit pas à la nouvelle direction de son voyage.

La lettre dont Votre Excellence reçoit ei-joint un duplicata, étoit un autre essai de me rapprocher de son souvenir. La voie dont jo me servois pour cette lettre, étoit si précaire, qu'il ne me restoit absolument que la faculté d'exprimer dans les termes les plus vagues le sentiment d'admiration, qui me pénétroit. Mais ceci même me parut un si grand soulagement que je voulois tout tenter plutôt que d'y renoncer.

Depuis cette tentative, et plusieurs autres, que je ne veux pas même indiquer i i, l'oeuvre de la destruction du continent s'est avancée avec une rapidité extraordinaire. Le trône d' Espagne a disparu; une grande partie de l'Italie a été directement ajoutée au territoire François; on a hautement déclaré, que toutes les côtes de la Méditerannée dovoient appartenir au prétendu Grand-Empire.

Dans tous ces nouveaux bouleversemens, une seule pensée m'a constamment occupé. Les événemens de l'Europe ne m'intéressent plus que sous un seul rapport, sous celui des effets qu' ils doivent produire hors de l' Europe. L' asservissement du continent est si complet, que quelque révolution de plus ou de moins, quelque trône renversé, quelque royaume englouti, ne signifie plus grand-chose. Ia véritable mesure de tout ce qui peut s'opérer aujourd' hui de changemens et de catastrophes sur le continent, est celle du contre-coup qui en résulte pour la situation des Deux-Indes, c' est-à-dire, celle de la force plus ou moins grande qui en revient à l'Angleterre, pour soutenir l'équilibre colossal (bien différent de l'ancien équilibre politique) auquel est attachée maintenant la dernière, la seule grande espérance de l' univers.

Considérée sous ce point-de-vue suprême la révolution que vient d'éprouver l'Espagne, sera pour moi une révolution funeste ou heureuse, suivant l' effet qu' elle opérera dans le sort de l' Amérique cj-llevant Espagnole. Si l'Angleterre parvient à fixer d'après ses principes (quelqu'ils soient), et d'après s es intérêts (qui seront toujours finalement les intérêts communs) les relations futures de ces vastes pays - acquérant par là, non seulement des avantages directs incalculables, mais encore le moyen le plus efficace de mettre un terme à la conduite équivoque des Etats-Unis, ot de réunir à sa cause la totalité de l'Amérique - si tel est le résultat de ce nouvel attentat, je déclarerai, que le jour, où Bonaparte a signé la chûte des Bourbons en Espagne, que ce même jour a commencé à s' exécuter l'arrêt de sa décadence progressive, fondéo sur les mêmes combinaisons, qui avoient amené son pouvoir monstrueux; et que nous touchons à l'époque de cette réaction, de cette contre-révolution universelle, nécessaire, inévitable, que les désordres et les souffrances du continent d' un côté, la persévérance de l' Angleterre de l' autre, doivent tôt ou tard réaliser et consommer.

3) S. o. S. 143, Anm. 2. Adair wurde englischer Gesandter in Konstantinopel. 
En-attendent la catastrophe de l' Espagne paroit aroir poussé quelques fruits tardifs au sein même de ce continent subjugué. D' après les données les plus authentiques et les plus respectables que j'ai pu recueillir, le Cabinet de Vienne en a été profondément affecté. $\mathrm{L}$ 'impression que ces événemens ont faite sur lui, s' explique plutôt, il est vrai, par la secousse qu'ils ont donnée à l'imagination, par les anciens et honorables souvenirs, par les tristes réflexions générales, qu'ils ont fait naitre, que par leur importance relative réelle; car il est bien certain, que l'Autriche a été moins consternée par des catastrophes beaucoup plus prochaines, plus directement menaçantes, plus capitales, si j' ose m' exprimer ainsi, que celle de ce moment. Mais quoiqu'il en soit, le coup est porté; et il est sûr, que depuis quelques mois, depuis le départ de Mr. Adair de Vienne les dispositions secrètes de cette cour sont essentiellement et considérablement changées. Je ne dis pas, qu' elle songera jamais à entreprendre quelque chose de son propre chef, pour sortir de la situation fatale de cet état-de-siège ou de blocus, où elle se trouve. C'est même un grand et terrible problême de savoir, si elle le peut, et si elle le doit. Mon opinion à moi est faite sur cette question. S'il se présente un Général, capable de donner aux troupes une impulsion extraordinaire, de les électriser, de les entrainer, de les enlever au point de s'en servir pour des opérations qui sortissent tout-à-fait de la règle commune - il faut prendre l'offensive dès ce moment; et les forces matérielles de l'Autriche, animées par une direction comme celle que je viens de définir, peuvent opérer dans deux mois une révolution totale sur le continent. Si au contraire tout reste dans les anciennes ornières, si l'armée est commandée par des Généraux qui ne savent ni s'élever eux-mêmes à des conceptions vastes et hardies, ni bien moins encore $\mathrm{y}$ associer les autres, en un mot, si nous ne sortons pas tout-à-coup de notre médiocrité habituelle et routinière par un effort majeur et décisif - il est plus sage d'attendre la chance de l'avenir ; car sans ces conditions préalables, le premier coup-de-canon dans une guerre active de notre part, est le signal de la destruction de la Monarchie.

Cependant ce n'est pas peu de chose que de voir au moins ce gouvernement, naguères si craintif, envisager la crise qui s' approche, avec une fermeté réelle et louable. Ce n'est pas peu de chose que de le voir positivement décidé à défendre ses droits et son territoire, à repousser la première agression, sous quelque forme et prétexte qu' elle s'annonce, à résister même à tout projet d'envahissement qui s'introduiroit par la voie des négociations, ou propositions amicales. Je crois que cette mêmo attitude, et les mesures qu' elle fera naitre incessamment, détermineront Bonaparte à ajourner ses projets contre ce pays. Si elles suffiront pour le sauver au jour de la décision finale, - est une question plus sérieuse et plus embarassante.

Je prévois au-reste que le Cabinet de Vienne fera tôt ou tard la même faute cruelle, qui a tant contribué aux malheurs de la Monarchie Prussienne. Il se trouvera aux prises avec les Français, sans avoir songé à se rapprocher de l'Angleterre. Je ne sais pas, quelle est aujourd' hui à Londres la manière d' envisager les affaires du continent: j'ignore surtout, quels sont à ce sujet les principes de Votre Excellence. Si après tant de ré- 
volutions qui ont absolument changé jusqu' aux bases fondamentales de la politique, le Gouvernement Anglois s' étoit décidé à abandonner une fois pour toutes le continent, je ne serois point étonné de cette résolution; des motifs d'une grande force et supériorité pourroient lui avoir donné naissance. Mais s'il en étoit autrement, — je suis bien intimément persuadé, que l'Autriche doit constamment être, first and last "dans les soins et dans les calculs de l'Angleterre. La Russie ne peut pas même entrer en comparaison avec ce pays-ci. Sous le rapport du commerce, elle intéresse l'Angleterre bien plus que l'Autriche; mais aussi sous ce meme rapport, elle ne peut jamais être perdue pour longtems; quelque-chose qui arrive en Russie, l'intérêt, le besoin, la nécessité, ramèneront toujours vers l'Angleterre. Mais sous les grands rapports politiques la Rassie est infiniment moins intéressante que l' Autriche. Nous avons aujourd' hui la mesure des forces réelles, la mesure de la capacité de [la] Russie d'agir à de grandes distances, la mesure de ses talens, de sa constance, de sa fidélité, de sa loyauté; j' espère bien, que dans aucun tems à venir personne ne sera plus la dupe de cette puissance. Elle est d'ailleurs, ceci est maintenant démontré, placée bien trop hors de la sphère des grands mouvemens qui décident les destinées de l'Europe, pour être regardée comme un poids de première importance. - Si jamais le continent doit se relever de sa châte, e' est par l'Allemagne que s'opérera la régénération universelle. Ce n' est pas une aveugle prévention, ce n'est pas la chimère d'un patriotisme exagéré; c' est le résultat des plus longues, et $j$ 'ose dire, des plus profondes recherches, que je Vous offre dans ce peu de mots. Tous les élémens de salut et de rétablissement sont réunis en Allemagne; il ne s'agit que de les vivifier. Or, comment cela seroit-il possible, si l'A u triche avoit disparu?

L'Autriche est donc aujourd'hui le seul et unique point du continent, qui mérite un intérêt et des soins soutenus. Et quand même on auroit pris en Angleterre, et justement pris le parti de ne plus se mêler directement des affaires du continent, je crois, qu' au moment redoutable, où le sort de l'Autriche sera décidé, un grand et généreux effort pour secourir cette puissance intéressante, ce dernier et noble débris de l'ancien systême continental (destiné peut-être à recommencer l'ordre politique, et à servir de base et de noyau aux nouvelles combinaisons qui se fonderont) - seroit de la part de l'Angleterre une mesure également recommandée par la magnanimité et la vraie politique.

J'insiste d'autant plus sur cet article, que je crois le Cabinet de Vienne, comme je l'ai déjà observé, assez loin d'une démarche sérieuse quelconque, qui pourroit remettre ses relations avec l'Angleterre; que je le crois même dans de fausses appréhensions sur la manière dont une démarche de cette nature seroit accueillie. J'ai de très bonnes raisons pour croire, que le dernier ministre de l'Autriche qui a résidé chez Vous 1), quoique fort attaché à l'Angleterre, et en général professant, et même avec chaleur, les principes politiques les plus purs, n'a pas fait de l'état actuel des choses à Londres un tableau particulièrement propre à inspirer

1) Ludwig Fürst Starhemberg. Vgl. seine Biographie von A. Graf Thür rhe im. Graz 1889 . 
de la confiance à l'Autriche. J'ai de bonnes raisons pour croire, qu'au contraire, piqué et dégouté par quelques désagrémens personnels, et d'ailleurs souvent très-leger, trés-emporté, et trés-partial dans ses jugemens '), il a peint les choses, et surtout les personnes, d'une.manière calculée plutôt à décourager le Cabinet de Vienne qu'à lui inspirer la confiance et l'espoir. - Ce n'est pas un vain commérage, que je fais ici; c'est un point de la plus haute importance, que je crois de mon devoir de relever, en ayant acquis une connoissance authentique et assez détaillée. Je sais bien, et je l'ajoute exprès, qu' on est loin a Vienne d'ajouter une foi implicite aux opinions et aux données de ce Ministre; mais elles forment toujours un obstacle de plus; et il est toujours bon et utile, et intéressant pour l' une et l'autre puissance, qu'à l'approche du moment décisif les obstacles réels déjà trop grands ne soient pas renforcés encore par des difficultés tout-à-fait imaginaires.

Voilà tout ce que dans l'incertitude de la situation de l'Autriche, et dans l'ignorance complète où je me trouve sur le systême et les dispositions présentes du Gouvernement Anglois je crois pouvoir dire sur les affaires du seul pays, resté debout dans la conflagration générale du continent. Le tems passe; et je demande la permission de revenir encore une fois sur l'Angleterre.

C'est un spectacle vraiment ravissant que de voir, combien peu-à-peu la conviction de la solidité inébranlable de l'Angleterre, et de l'inutilité de tous les efforts, imaginés par son cruel ennemi, s'empare de tous les bons esprits et gagne même les foibles et les lâches au point de les faire trembler sur l'avenir, s'ils sont dans les intérêts de la France, ou de leur rendre une partie de leurs forces, s'ils n'ont pas cessé de désirer un changement. La simple persévérance - nous le savions depuis longtems, mais jamais un exemple plus brillent ne l'avoit aussi sensiblement inculqué au monde - la simple persévérance est un pouvoir d' une énergie prodigieuse. Chaque courier, chaque gazette, ne fît-elle que renouveler au continent la certitude - que l'Angleterre n'a pas changé - est d'un poids incalculable dans sa balance. Les badauds du continent avoient imaginé tout-de-bon que le systême d'exclusion générale, aussitôt qu'il seroit connu en Angleterre, y ameneroit une révolution complète. Votre réponse au manifeste de la Russie, le calme, la dignité imperturbable, avec laquelle Vous contempliez la défection de l'Autriche, de la Prusse, etc. les mesures par-rapport à la navigation, et plusieurs autres symptomes expressifs commencèrent, il est vrai, à dèranger un peu l'sveuglement général. Mais enfin, attendons encore quelques momens, se disoit-on; les adresses pleuvront de toutes parts sur le parlement; les fonds baisseront; des emprunts énormes ne pourront plus combler le déficit; les Catholiques d'Irlande remueront; l'opposition saura culbuter ces ministres, et alors tout pliera sous Bonaparte. Toutes ces vaines attentes sont aujourd'hui déjouées. Pas une seule adresse de quelque poids n'est venue à ce qui paroit, Vous alarmer; les fonds sont montés jusqu'au taux extraordinaire de 68, qu'ils n'ont jamais atteint (pour autant que je me le rappelle) dans aucun moment de guerre ou de paix, pendant toute la durée des

2) Vgl. Wertheimer a. a. O. II. 221. 
deux administrations de $\mathrm{Mr}$. Pitt; cet emprunt de 45 millions, que les feuilles Françaises avoient annoncé ${ }^{1}$ ) - fable ridicule, qui n'en a imposé un moment qu'à la populace - est démenti par les articles (tronqués défigurés, mal-traités de toutes les manières, mais toujours encore précieux) que quelques gazettes Allemandes fournissent de tems en tems à travers mille déguisements; les Catholiques d'Irlande sont moins turbulens que jamais; et quant aux attaques de l'opposition, elles ne peuvent être ni mortelles, ni même très formidables, puisque si elles l'étoient, le Moniteur et ses dignes confrères n'auroient certainement rien de plus pressé, que de nous en régaler chaque matin. Je donnerois une année de ma vie, si je pouvois obtenir quelques renseignemens authentiques sur tous ces articles intéressans, et principalement sur celui des finances; mais même le peu d'instruction que je possède dans ce moment, me suffit pour tracer au-moins les grands traits du tableau; et je puis me vanter d'en tirer un avantage prodigieux pour éclairer, ou pour ranimer une quantité de monde.

Une lettre qui m'est venue de Hollande il y a quelques semaines m'a instruit, d' une manière obscure, il est vrai, mais cependant très intelligible, de deux choses d'un grand intérêt pour moi. D' abord des mesures, que Votre Excellence a daigné prendre, pour réaliser tout ce que j' avois demandé et sollicité depuis le mois d'Aout 1801; mesures, dont je suis trop foible pour exprimer toute ma reconnoissance ${ }^{2}$ ). - Mais en second lieu, on m'avertit de ne jamais songer à un voyage en Angleterre ${ }^{3}$ ), avant que je n'aie reçu à ce sujet certaines informations particulières qui me parviendroient tôt ou tard.

Ce dernier objet est pour moi d' une importance extrême. Je nourris sans-cesse le projet d'aller en Angleterre, premièrement, parce que, si tant est que je puisse encore être utile, je ne pourrai l'être que dans ce pays; secondement, parce que le grand ouvrage qui $m$ ' occupe aujourd' hui - l'exposition approfondie de toutes les questions sur le droit des neutres dans les guerres maritimes ${ }^{4}$ ) - ne peut ni s'achever, ni sur-tout se publier ailleurs qu' en Angleterre; troisièmement, parce que d'après la tendence générale des événemens le moment approche à grands pas, où je n'aurai plus d'autre asyle sur la terre. - Par toutes ces raisons je prie, et je conjure Votre Excellence, de profiter de la première occasion sûre, qui se présentera pour communiquer avec le continent, et de $\mathrm{m}$ 'adresser quelques mots seulement qui puissent me servir de guide. Jusques là je serai immobile à Prague ou à Vienne, (ce qui pour la correspondance revient au même) à-moins que des événemens inattendus, mais peu vraisemblables pour cette année-ci ne me forcent de quitter ce pays.

La confiance que $m$ 'inspire la noblesse et la grandeur de Votre ame, est telle, que j'ai le courage de vous parler encore en faveur d' un individu, qui, sans Votre puissante protection, sera peut-être bien malheureux

1) Ms. annoncées.

2) Vgl. o. S 147, Anm. 2.

s) Vgl. o. S. 148, Anm. 1.

4) Die beiden ,Mémoires sui les droits maritimes" (abgedruckt bei $\mathrm{Schle-}$ s i e r: Mémoires et Lettres inédits du chevalier de Gentz 1841 S. $347 \mathrm{ff}$., $389 \mathrm{ff}$.) wurden erst im Jahre 1812 niedergeschrieben rgl. Gentz: Tagebücher I. 258. 
aujourd' hui. C' est un homme qui s' appelle Antoine Urans (il est très connu à Mr. Hammond) qui a été souvent employé comme courier par les ministres d' Angleterre à Vienne, qui a fait en dernier lieu un séjour à Londres par dévouement pour moi, et qui à son retour a été arrêté en Hollande. A en juger d' après un article que j' ai trouvé dans les gazettes, je présume qu'il a trouvé le moyen de s'échapper et de se sauver en Angleterre. Mais si cela est, il y sera sans moyens de subsistance. Daignez, Monsieur, faire quelque chose pour ce malheureux qui pour peu que Vous veuilliez l'employer pourra Vous rendre de très-bons services, et pour lequel je m' intéresse comme s'il étoit mon frère; tant il m' est cher par un attachement à toute épreuve.

Un voyægeur an milieu d' un terrible désert ne peut pas soupirer après une source d'eau-vive, comme je soupire après quelques lignes de consolation ou d'instruction de Votre part. Si Votre Excellence en trouve le moyen, je sais, qu'Elle se souviendra de moi. En-attendant je n'en négligerai aucun, pour me rappeler à Son souvenir, mais surtout aucun, pour le mériter. Pénétré du bonheur de pouvoir m'adresser à un homme, dont le nom va occuper une des pages les plus brillantes de l' histoire, je Vous prie, Monsieur, d'agréer avee bienveillance l' hommage du dévouement aussi respectueux qu' inviolable, avec lequel je suis

De Votre Excellence

Le très-obéissant et très-fidele serviteur

Gentz. 